\title{
The other 99\%: exploring the arthropod species diversity of Bukit Timah Nature Reserve, Singapore
}

\author{
J. K. I. Ho ${ }^{1}$, M.S. Foo 2 , D. Yeo ${ }^{1}$, R. Meier ${ }^{1}$ \\ ${ }^{1}$ Department of Biological Sciences, 14 Science Drive 4, \\ National University of Singapore, 117543 Singapore \\ meier@nus.edu.sg \\ ${ }^{2}$ Lee Kong Chian Natural History Museum, 2 Conservatory Drive, \\ National University of Singapore, 117377 Singapore
}

\begin{abstract}
Bukit Timah Nature Reserve (BTNR) is one of Singapore's most important conservation areas because it is likely to be the last refuge for many species that belong to Singapore's original forest biodiversity. We report here the results obtained from a first broad-scale survey of arthropods in BTNR. The focus was on insects because Singapore's insect fauna remains largely unknown despite the fact that insects constitute much of the animal biomass and perform many ecologically important tasks. The survey relied on specimens collected with passive traps (e.g., Malaise traps) that were set along several transects in primary and different types of secondary forests. Specimens representing several thousand species were obtained. In order to process the specimens rapidly, we sorted them based on DNA sequences of the COI gene. Sequences for more than 9,000 specimens were obtained and the DNA data were used to group the specimens into putative species. Here, we compare the species numbers, composition, and species overlap between secondary and primary forests for "true bugs" (Hemiptera). Overall, the sequences belonged to more than 1850 insect species of which ca. 450 belonged to Hemiptera. A very large proportion of the "true bug" species are only represented by 1 or 2 specimens each and we find that BTNR's species diversity is much higher than the diversity in mangroves and on the National University of Singapore (NUS) campus. We also report and illustrate some notable insect species found during the survey. They range from ship-timber beetles to beetle-flies mimicking leaf beetles and mantis-flies resembling praying mantises.
\end{abstract}

Keywords: Biodiversity, Hemiptera, invertebrate sampling, Next Generation sequencing, tropical rain forest

\section{Introduction}

Bukit Timah Nature Reserve (BTNR) is both the first and oldest Nature Reserve in Singapore. It has been under some form of protection since at least 1882 (Corlett, 1988). Today, it is under the care of the National Parks Board, Singapore, which is responsible for its management according to the Parks and Trees Act 2005 (Chan \& Davison, 2019). This long-term protection has ensured that several patches of primary forest have survived. Additionally, much of the remaining reserve is covered by old secondary forest which is in many places surrounded by young secondary 
forest. BTNR and the adjacent Central Catchment Nature Reserve (CCNR) are thought to be a refugium for many forest-dwelling species that have gone extinct elsewhere in Singapore. These include charismatic species such as the Blue-Winged Leafbird Chloropsis cochinchinensis (Lim, 2019) and Wagler's Pit Viper Tropidolaemus wagleri (Teo \& Thomas, 2019), but BTNR is also likely to be a refugium for many arthropod species that perform important ecosystem services such as pollination and the decomposition of organic matter. In addition, BTNR is also an internationally important study site in tropical biology because the reserve is one of the few places worldwide where a small fragment of unlogged rain forest is embedded in an urban and semi-urban land matrix (Corlett, 1988). Thus, BTNR is routinely included in studies investigating the results of forest fragmentation on biodiversity (Turner \& Corlett, 1996; Ercelawn et al., 1998; Brook et al., 2003; Goldsmith et al., 2011; Ho et al., 2019). BTNR also hosts a long-term survey plot belonging to the forest dynamics programme of the Forest Global Earth Observatory (ForestGEO), formerly known as the Smithsonian Center for Tropical Forest Science (Ashton et al., 1999).

Due to these studies, BTNR has been described as the "best studied forest area in Southeast Asia" (Henderson, 2000). However, these studies have focused on the plant or vertebrate diversity, leaving much of the invertebrate diversity unknown. Exceptions include a few selected groups of arthropods (e.g., butterflies, stick insects, decapod crustaceans: (Balke et al., 1997; Murphy, 1997; Ng, 1997; Seow-Choen, 1997; Yang et al., 1997) for which the fauna of BTNR was included in studies that also investigated the diversity of CCNR and/or Singapore. In addition, BTNR-specific checklists exist for a few groups of insects (Tan, 2012a, 2012b; Ong et al., 2013), and additional information is available from studies that used BTNR sites for investigating insect ecology (Liow et al., 2001; Lee et al., 2009). Despite all these studies, much of the invertebrate diversity of BTNR remains unknown. This is problematic for several reasons. Firstly, most of the species-level animal diversity consists of insects. According to the latest estimates, there are more than 5.5 million species of insects on this planet (i.e., about 100 times the number of vertebrate species) of which more than $80 \%$ are currently unknown to science (Stork et al., 2015; Stork, 2018). These insects perform numerous tasks that are critical for the survival of more charismatic biodiversity such as trees and vertebrates. Secondly, it is estimated that all terrestrial invertebrates combined constitute over 20 times the biomass of all terrestrial vertebrates (Bar-On et al., 2018); i.e., ignoring the invertebrate biodiversity means ignoring most of the animal biomass in BTNR and Singapore.

Unfortunately, discovering and identifying invertebrates has historically been very difficult due to the large number of species that need discovery/description and the small number of experts available for carrying out this research. This mismatch between the number of species and the availability of taxonomic expertise is responsible for the poor knowledge of the arthropod fauna of Singapore and elsewhere (Green, 1998; Giangrande, 2003; Kim \& Byrne, 2006). Fortunately, there are now ways to overcome some of these problems. Species discovery/identification can be thought of as a three-step process. The first step is obtaining specimens, the second is grouping the specimens into species, and the third is obtaining names for the species: 
Obtaining specimens is the first and most straightforward step. For arthropods, many species can be sampled with minimally-invasive passive traps such as Malaise traps that resemble tents that are pitched in the forest. Only those insects that fly into these "tents" are collected; i.e., only very small number of individuals are collected.

The second step is grouping specimens into species. This is a gargantuan task if the number of specimens and species is high. The task is particularly difficult to accomplish with morphology because it requires a large number of highly trained taxonomists who are familiar with the morphology of the different kinds of animals. It is here that new technologies can help. Most species can be distinguished and thus sorted by using so-called "DNA barcodes". The most commonly used DNA barcode for animals is a fragment of the cytochrome oxidase subunit I (COI) gene that is also known as the 'DNA barcode' (Hebert et al., 2003). Biologists can now use such COI sequences to group specimens into putative species as long as the DNA sequence for specimens differ by up to $3 \%$. This means that sorting specimens into putative species does not require a large number of highly trained taxonomists. However, until recently a major problem with DNA barcodes was the high cost of sequencing. Fortunately, we have been able to overcome this problem by simplifying the process and using cost-effective sequencing technologies (Meier, 2008; Meier et al., 2006, 2016; Wong et al., 2014; Wang et al., 2018; Srivathsan et al., 2018).

The last step of species discovery/identification is identifying those species that have already been described by scientists and describing those species that remain unknown to science. This last step requires the help of trained taxonomists who specialize in different groups of insects and yields the formal scientific names of the species. Unfortunately, formal description usually requires years of study. Hence, species names are often only available several decades after a specimen has been collected. Fortunately, this third step of the species discovery process does not have to be completed before species numbers and species overlap between different habitats can be compared. These tasks can be accomplished based on DNA sequences alone, which is the approach that we are taking here.

The current study is part of a larger species discovery programme in Singapore that focuses on invertebrates but also includes population-level work on conservation priority species (Cranston et al., 2013; Tay et al., 2016; Wong et al., 2017; Baloğlu et al., 2018; Kutty et al., 2018; Wang et al., 2018; Yeo et al., 2018). This programme started with collecting specimens from many different habitats in Singapore. More than 100,000 specimens have now been sequenced that belong to more than 7000 species of insects. These include many new species that are in the process of being described. Some of these descriptions have already been published (Grootaert, 2006, 2018; Shamshev \& Grootaert, 2007; Zhang et al., 2008; Grootaert \& Puniamoorthy, 2014; Grootaert \& Shamshev, 2015). In this paper, we discuss preliminary results of the BTNR arthropod survey, as well as its implications for biodiversity discovery and conservation in Singapore. 


\section{Methods}

As part of the Bukit Timah insect survey, more than 10,000 arthropod specimens from BTNR were sequenced. The specimens were obtained using Malaise traps that were placed along transects in (1) primary forest, (2) old-growth and (3) young secondary forest (see Chan \& Davison (2019) for the mapping of vegetation types and trail system in BTNR). Malaise traps were deployed at three sampling sites per habitat, resulting in a total of nine sampling sites throughout BTNR. All sampling was carried out from August 2016 to October 2017 and the specimens were stored in moleculargrade ethanol. After collection in the field, all specimens were pre-sorted taxonomically to major taxonomic group by trained students and interns. Afterwards specimens belonging to selected arthropod taxa were barcoded. All DNA barcodes in this project were generated through amplifying the COI mitochondrial gene using techniques described in Wang et al. (2018). In brief, for some specimens we used direct PCR (Wong et al., 2014) which utilises a small piece of tissue as DNA template while in other cases we used QuickExtract ${ }^{\mathrm{TM}}$ DNA Extraction Solution (EPICENTRE Biotechnologies) for obtaining DNA. The only barcoding gene used in this project was a short fragment of the COI mitochondrial gene $(313 \mathrm{bp})$ which was obtained using tagged amplicon sequencing as described in Wang et al. (2018). Downstream sequencing utilized high-throughput, paired-end next-generation sequencing (NGS) on IlluminaTM platforms. NGS was used as the main method of generating genetic sequences as it allowed for the rapid generation of large numbers of sequences at reasonable cost (Wong et al., 2014; Srivathsan et al., 2015; Wang et al., 2018).

All sequences were aligned using MAFFT version 7.0 before being grouped into putative species units that are usually called "molecular operational taxonomic units" (MOTUs). Grouping was accomplished using objective clustering which groups sequences by similarity based on uncorrected pairwise (p) distances (Meier et al., 2006; Srivathsan \& Meier, 2012). Stable clusters across the 2-4\% distance range are likely to represent species and we therefore used these thresholds for clustering specimens into MOTUs. Additionally, intraspecific and interspecific variability was used to assess species boundaries (Meier et al., 2008). As a working hypothesis, we here used 3\% sequence differences for separating putative species. This threshold is frequently used in the literature because it maximizes congruence between morphology and sequence data (Meier et al., 2008; Wang et al., 2018).

All specimens were deposited in the Lee Kong Chian Natural History Museum (LKCNHM) where they are available for study by taxonomic experts. For many MOTU/species, one specimen of each was imaged utilising a high-resolution photomacrography system (Visionary DigitalTM Lab Plus System, Arizona, USA) at high magnification and with different focal depths. Multiple images were then digitally stacked into a single, sharp composite image using Helicon Focus Pro (HeliconSoft, Ukraine). Afterwards, the composite images were digitally optimised in Photoshop CS5 Extended (Adobe, USA). Depending on the taxon, the specimens were imaged in different orientations and magnifications in order to illustrate key diagnostic features. Separate images were then digitally stitched together and 
uploaded on the website "Biodiversity of Singapore" (https://singapore.biodiversity. online/), which allows for the dissemination of biodiversity information to the public and makes high-resolution images available to taxonomic experts around the world that can provide identifications to different taxonomic levels (Ang et al., 2013a, 2013b).

\section{Results}

\section{Overall barcoding results}

For this preliminary survey, we sequenced selected groups of arthropods. This included several taxa of Diptera (flies), Hemiptera (true bugs), Hymenoptera (in particular ants, bees and wasps), and Araneae (spiders: rare in Malaise traps). Nearly 10,000 specimens were successfully barcoded, with each successful DNA barcode having a length of c. 313 base pairs. Out of the specimens successfully barcoded, 5413 were Diptera (flies), 2621 Hemiptera (true bugs), 1442 Hymenoptera (ants, bees and wasps), and 381 Araneae (spiders).

Upon analysis, 1898 putative species, or MOTUs (Molecular Operating Taxonomic Units) across all four taxa were obtained using a 3\% cluster separation threshold. Based on previous work, we estimate that c. $90 \%$ of these units are congruent with species delimited based on morphology (Wang et al., 2018). In order to test whether the number of species is dependent on clustering thresholds, we also used a 2\% cluster separation threshold which yielded 1942 MOTUs and a 4\% threshold that yielded 1882 MOTUs (Table 1); i.e., the estimate of species numbers is very stable. Out of these putative species, about 1000 are singletons, that is to say species known only from one specimen. This suggests that about half of the putative species recorded are rare. This is typical for arthropod samples (Coddington et al., 2009; Lim et al., 2012).

\section{Hemiptera: A case study}

Hemiptera, also known as the true bugs, are a group of insects that are characterised by long, stabbing mouthparts. While relatively common and diverse, Singapore's hemipteran diversity - especially the terrestrial species - has received very little attention although many species are known to be important plant pests that can transmit plant viruses. Using the data collected during the course of this project, we here present an estimate of the overall hemipteran diversity of BTNR and examine the distribution of species between different habitats in BTNR.

For Hemiptera, a total of 467 MOTUs were obtained using a 3\% cluster separation, and 230 of these MOTUs were singletons. At $2 \%$ sequence divergence, 474 MOTUs were obtained with 237 of them being singletons. Finally, 460 MOTUs and 227 singletons were obtained at 4\% cluster separation. Overall, this implies that the collected specimens belonged to at least 400 species (Table 2). About $50 \%$ of the putative species were singletons.

We also studied the distribution of the different species across three forest types in order to determine if there was any particular pattern to the species distribution. This 
Table 1. Overall putative species numbers/MOTUs of all four taxa barcoded with different cluster separation thresholds.

\begin{tabular}{lccc}
\hline Cluster separation & $\mathbf{2 \%}$ & $\mathbf{3 \%}$ & $\mathbf{4 \%}$ \\
\hline No. of putative species & 1942 & 1898 & 1882 \\
Singletons & 1037 & 988 & 982 \\
\hline
\end{tabular}

Table 2. Overall putative species numbers/MOTUs of Hemiptera barcoded with different cluster separation thresholds.

\begin{tabular}{lccc}
\hline Cluster separation & $\mathbf{2 \%}$ & $\mathbf{3 \%}$ & $\mathbf{4 \%}$ \\
\hline No. of putative species & 474 & 467 & 460 \\
Singletons & 237 & 230 & 227 \\
\hline
\end{tabular}

analysis was carried out twice; once based on all species, and once based on only those species for which more than five specimens were sequenced. This is advisable because it takes at least three specimens from a species before it can be shown to be shared between all three habitat types. We find that most Hemiptera species were found in maturing secondary forests, followed by primary forest and old secondary forest. Each habitat shared about 100 species with each other, but many species are also unique to each habitat (Fig. 1). Many of these "unique" species are eliminated when rare species were excluded from analysis (Fig. 1). This suggests that many of the species that were only collected once in a single habitat may eventually also be found in other habitats if sampling were increased.

Given that we suspected undersampling, we also prepared a species accumulation curve for hemipterans in BTNR (Fig. 2). The lack of a plateau indicates that many additional species are likely to be discovered if sampling were to be increased. The curve also reveals that the species diversity in BTNR is much higher than in other habitats in Singapore such as mangroves, Nee Soon freshwater swamp forest, or disturbed forest sites (NUS campus). Further information on the distribution of Hemipteran species within and between forest types is given in Fig. 3-6.

\section{Some notable insect finds in the BTNR samples}

The survey recorded many insect species and quantitative analyses will continue for many years to come. While these analyses are still ongoing, we can already feature some interesting finds. Most of these species have never been barcoded before, and several of these species may also be new to science. 


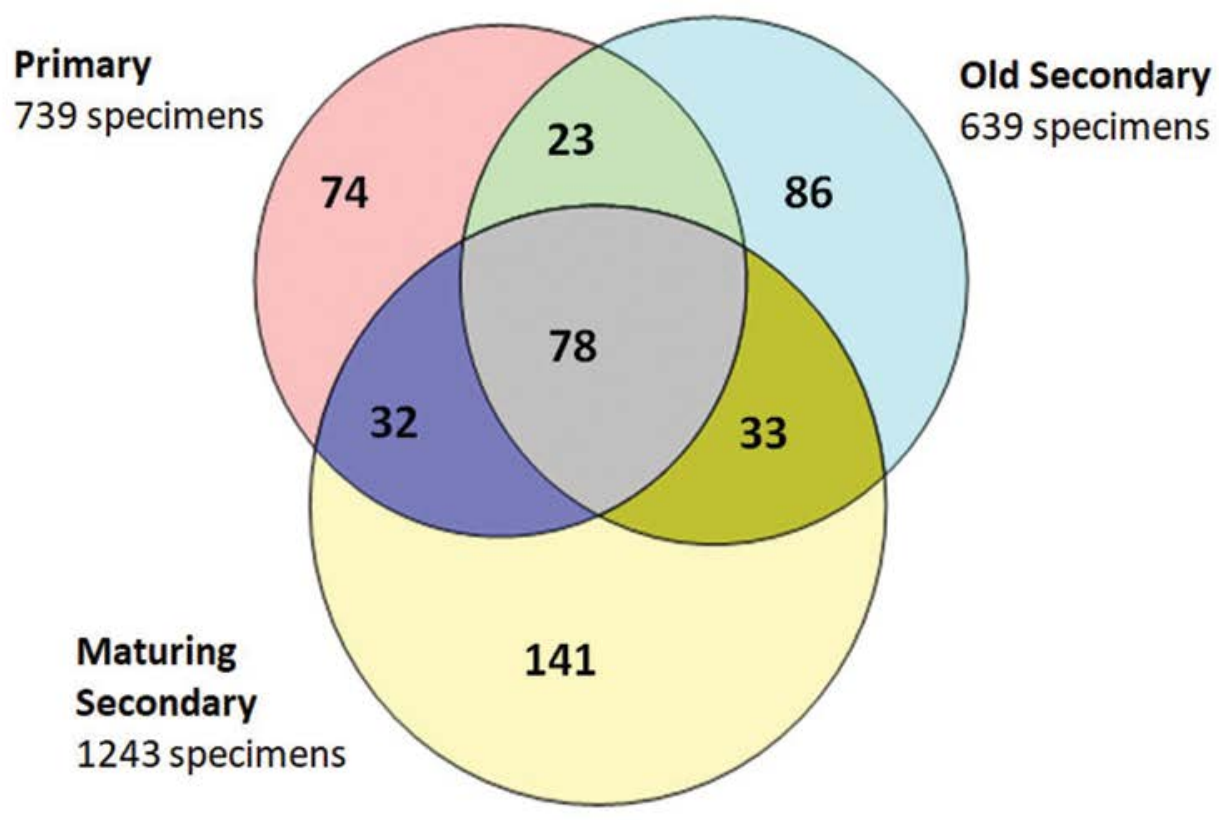

B

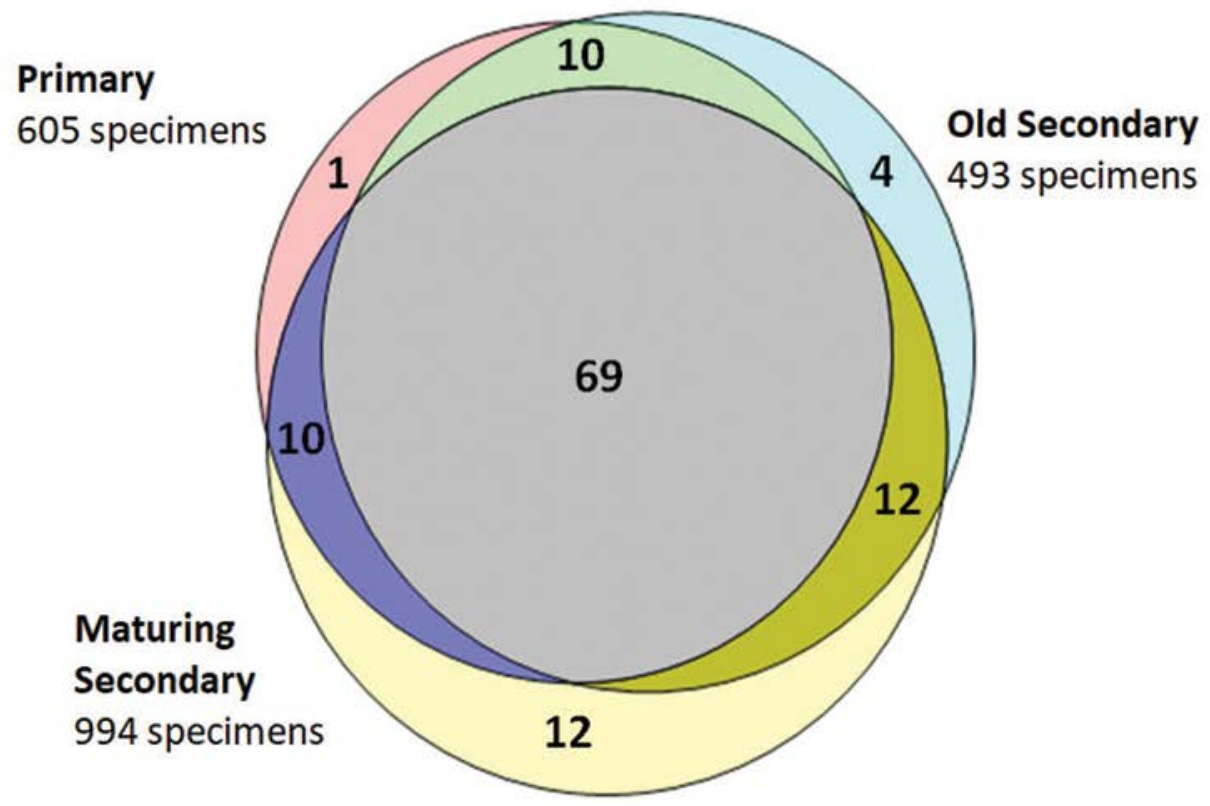

Fig. 1. A. Species overlap for all putative Hemiptera species detected during the BTNR survey. B. Species overlap for all of the putative Hemiptera species detected during the survey that have $>5$ specimens. Numbers and size of set indicate how many species are unique or shared between habitats. 


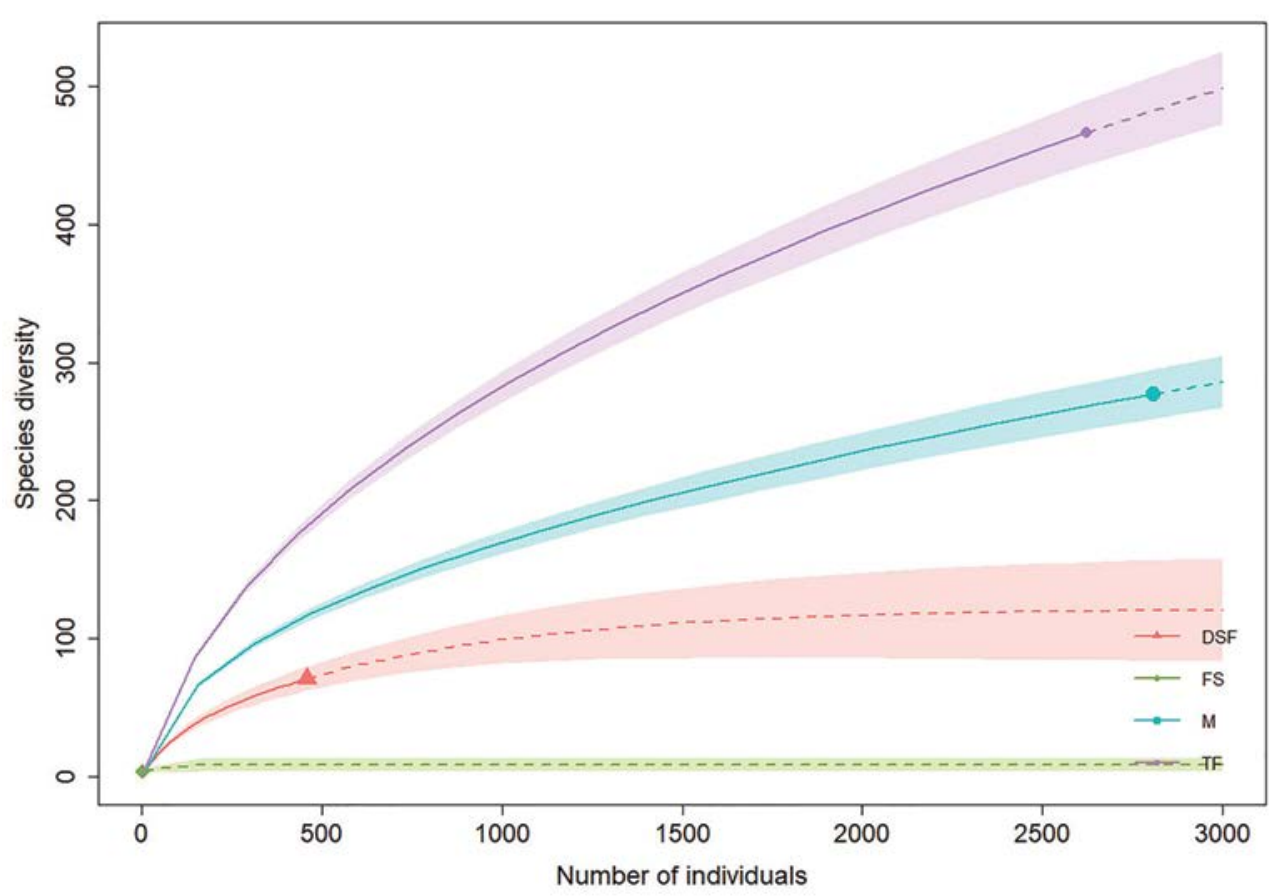

Fig. 2. Species accumulation curve of Hemipterans for four habitats in Singapore (TF: tropical forest [BTNR], FS: freshwater swamp, DSF: disturbed secondary forest (NUS campus), and M: mangroves).

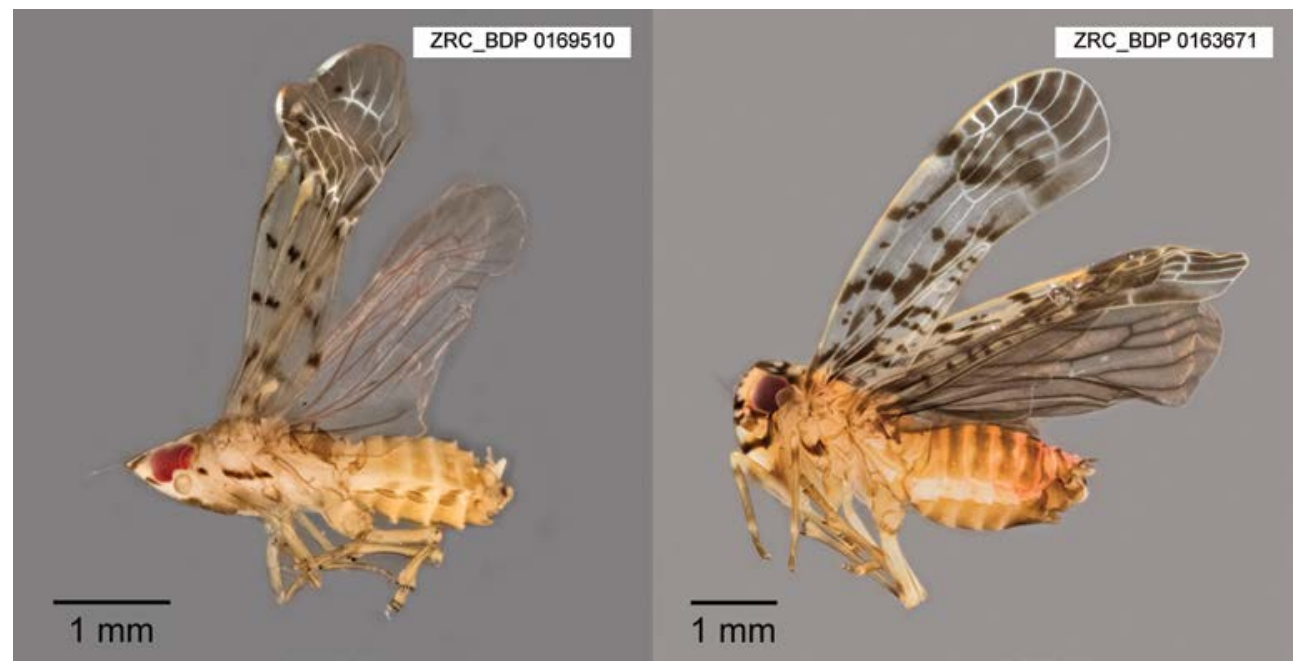

Fig. 3. Hemipterans found in all three habitats of the BTNR. These species are likely to be generalists, as they are not limited to a single habitat. (Photo: H. Siti Maimon) 


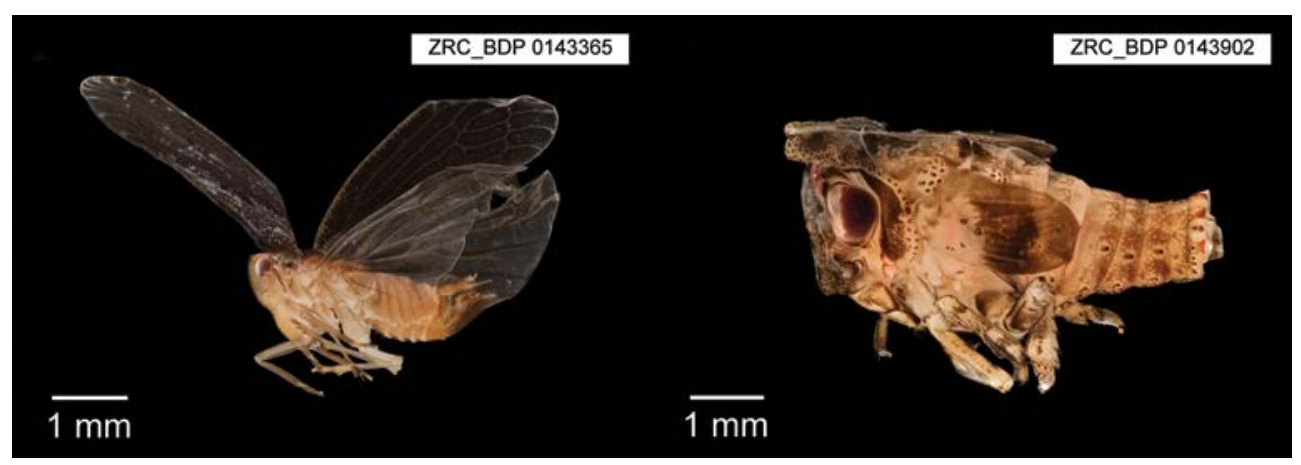

Fig. 4. Hemipterans found only in the primary forest habitats of the BTNR. These species are likely to be more selective in the environment that they require for survival. (Photo: H. Siti Maimon)

\section{Diversity in form and function}

Coleoptera (beetles) are currently considered the most species-rich insect group on earth although Hymenoptera and Diptera may eventually be found to exceed Coleoptera in species diversity (Forbes et al., 2018). Coleoptera currently account for $25 \%$ of all described species with species richness estimates indicating that there may be 1.5 million species of beetles (Stork et al., 2015). With such high diversity, it should not be surprising to find that beetles have important impacts on ecosystems. Many are herbivores, while others are voracious predators. All of them play an important part in the food web in any given ecosystem. Beetles pollinate plants, clean up decaying matter, while being food for many other animals. The sheer number of niches that beetles fill is impressive. Beetle diversity can thus also be used as an indicator of ecosystem health. Most beetles are capable of flight although only one pair of wings creates most of the lift. The second pair has been modified into thickened protecting organs known as elytra. The presence of elytra is the distinctive trait of the Coleoptera, and the characteristics of the elytra help to define the families mentioned below.

\section{Buprestidae (Jewel beetles)}

Jewel beetles are among the most spectacular of insects. Fig. 7 shows two examples from BTNR. Their beauty led them to be collectors' favourites, and they are occasionally used to make jewellery or art (e.g. Damien Hirst's "Capaneus"). The iridescent colour of the cuticle is a good example of structural colour that is generated by reflecting light at different angles. There are a variety of structural colouration techniques across Coleoptera. They include multilayer reflectors, threedimensional photonic crystals, and diffraction gratings (Seago et al., 2009). The larvae of jewel beetles feed on decaying wood, and some species are serious economic pests. However, other species are now under threat due to over-collecting. The status of Buprestidae in BTNR has been documented by Cheong (2019), and our molecular screening will supplement his findings. 


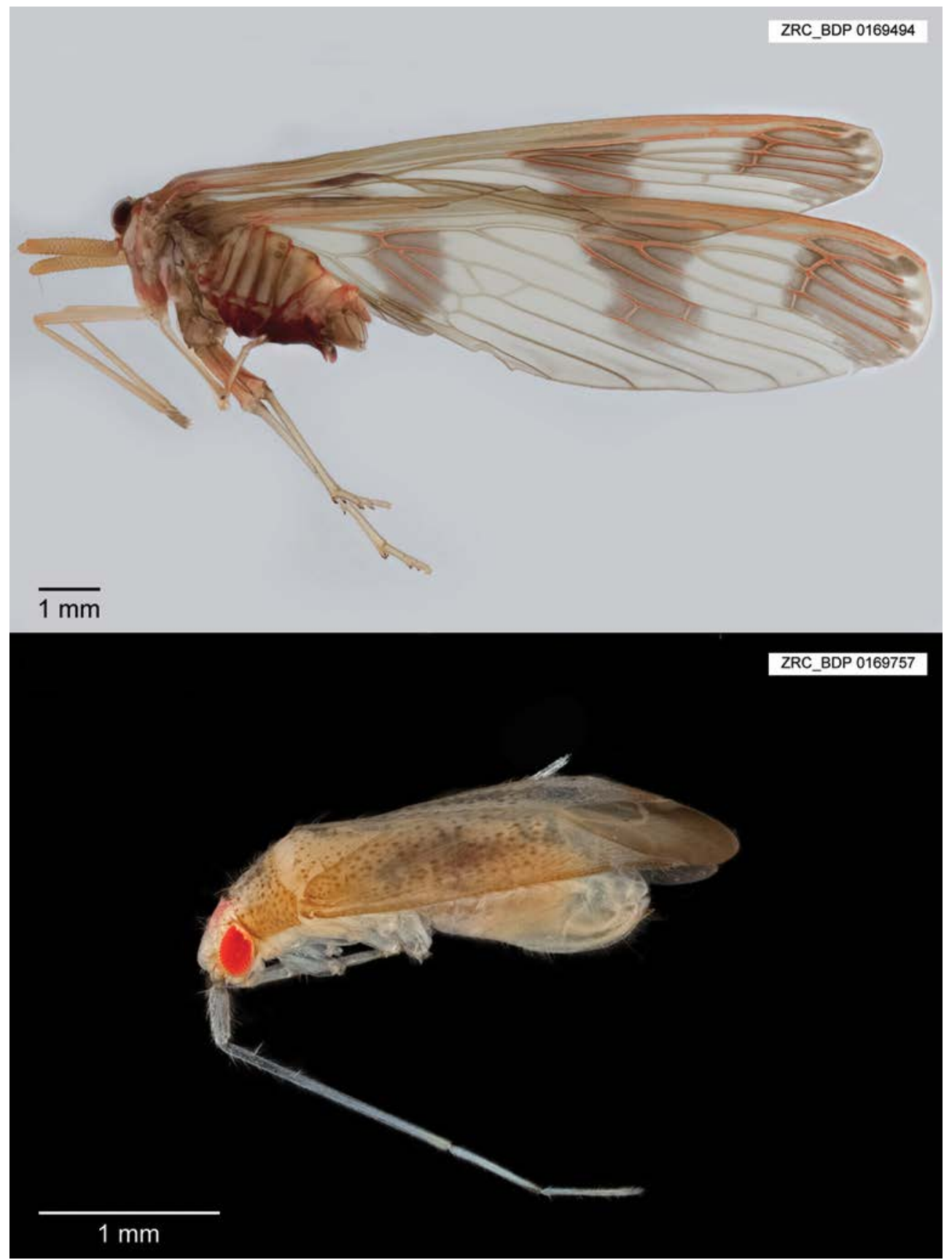

Fig. 5. Hemipterans found only in the old secondary forest habitats of the BTNR. These species can probably tolerate a little more disturbance compared to species limited to primary forests. (Photo: H. Siti Maimon) 


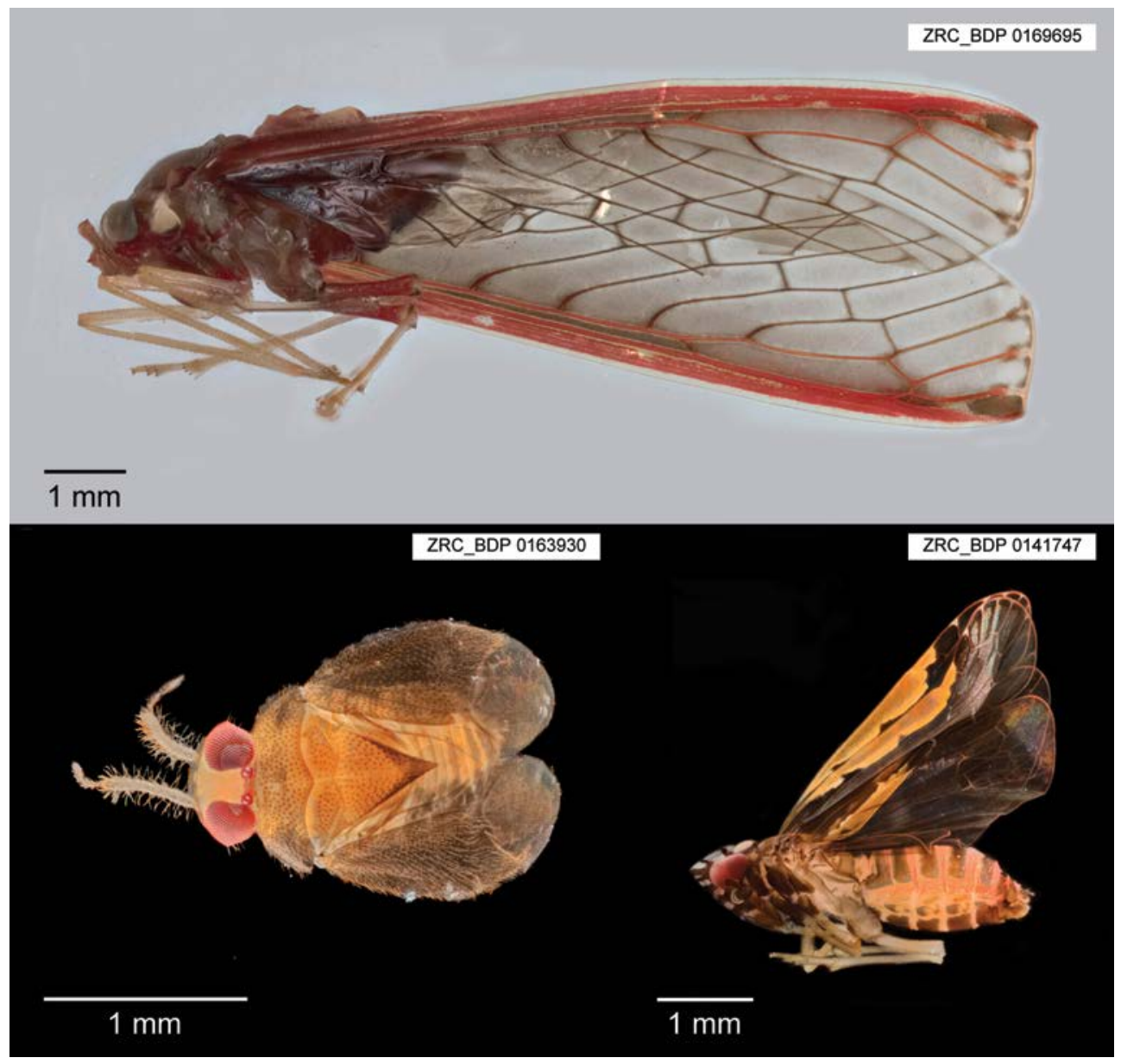

Fig. 6. Hemipterans found only in maturing secondary forest habitats of the BTNR. These species are probably more adapted to regenerating habitats, like the maturing secondary forest, compared to stable ones like the primary forest. This habitat also has the largest number of species. (Photo: H. Siti Maimon)

\section{Staphylinidae (Rove beetles)}

Rove beetles are one of the most species-rich groups of beetles. Fig. 8 shows two examples from BTNR. At last count, there were about 63,000 described species belonging to thousands of genera. This staggering number of species means that there is more than one described rove beetle species for each described vertebrate species. However, almost nothing is known of the vast majority of rove beetles, and most species remain undescribed. Rove beetles have a wide variety of body shapes, but the elytra of most species are shortened and do not cover the entire abdomen that tends to be long and flexible. This is likely an adaptation to their environment, as most rove beetles are terrestrial, living under stones and in leaf litter. Many of them are predators, preying on other insects which share their environment. A large number of the species in BTNR are very small. 


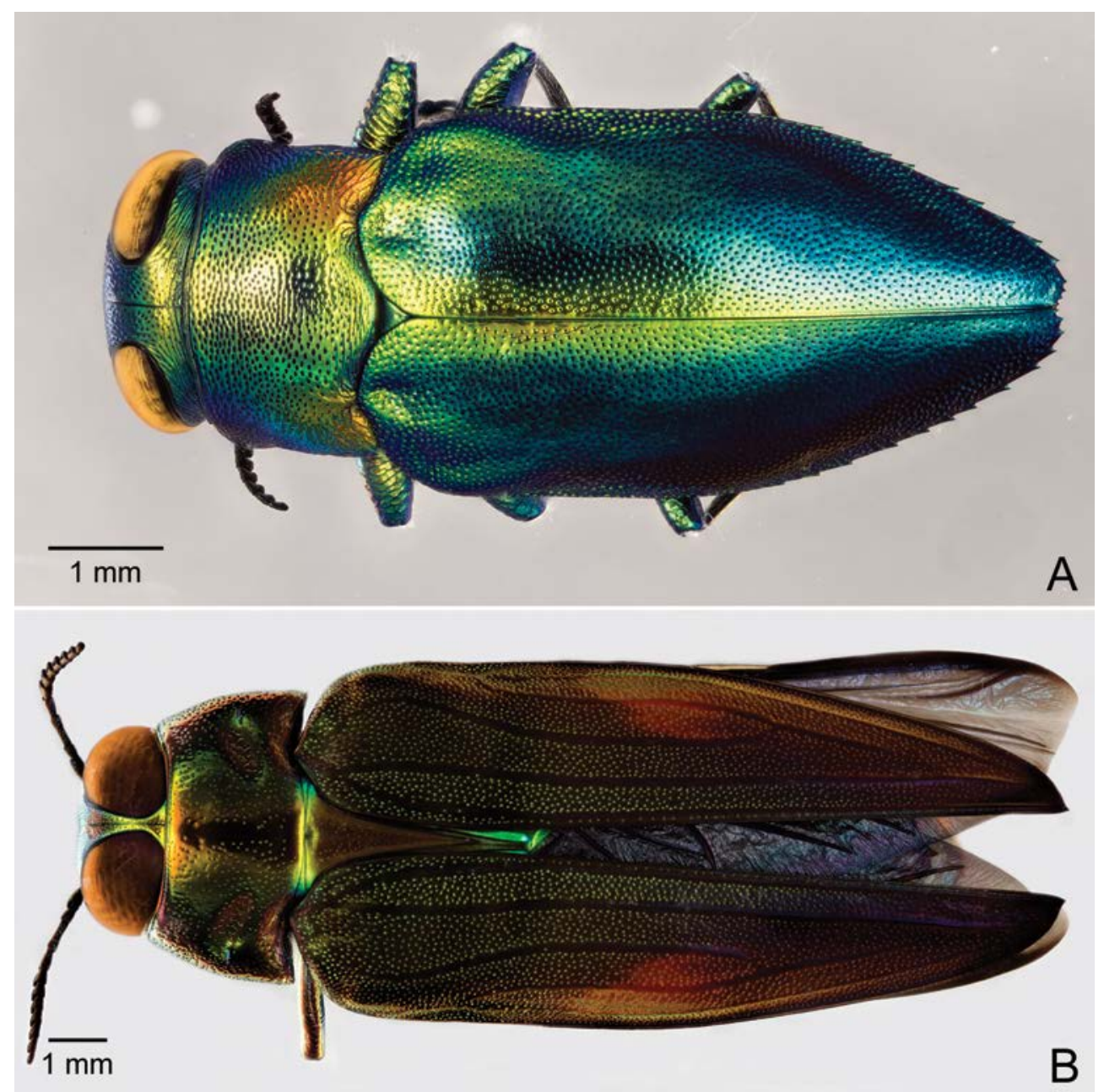

Fig. 7. Examples of Buprestidae species found during the BTNR survey. Species A is from the genus Chrysobothris while species B is Belionota metasticta. (Photo: H. Siti Maimon)

\section{Lymexylidae (Ship timber beetles)}

Lymexylidae are another family of beetles with larvae that feed on wood by boring through it. Some species are also known to have a symbiotic relationship with fungi, the larvae spreading the spores of fungi via tunnels. The larvae are then known to return to feed on the mycelium. There have been anecdotal reports of these beetles in Singapore before now, but we have now collected a specimen in BTNR (Fig. 9).

\section{Hybosoridae (Scavenger scarab beetles)}

The Hybosoridae are an obscure group of beetles which usually feed on carrion, dung, or other decaying material. Some adults - such as the one depicted here - have the ability to roll up into a ball for protection (Fig. 10). 


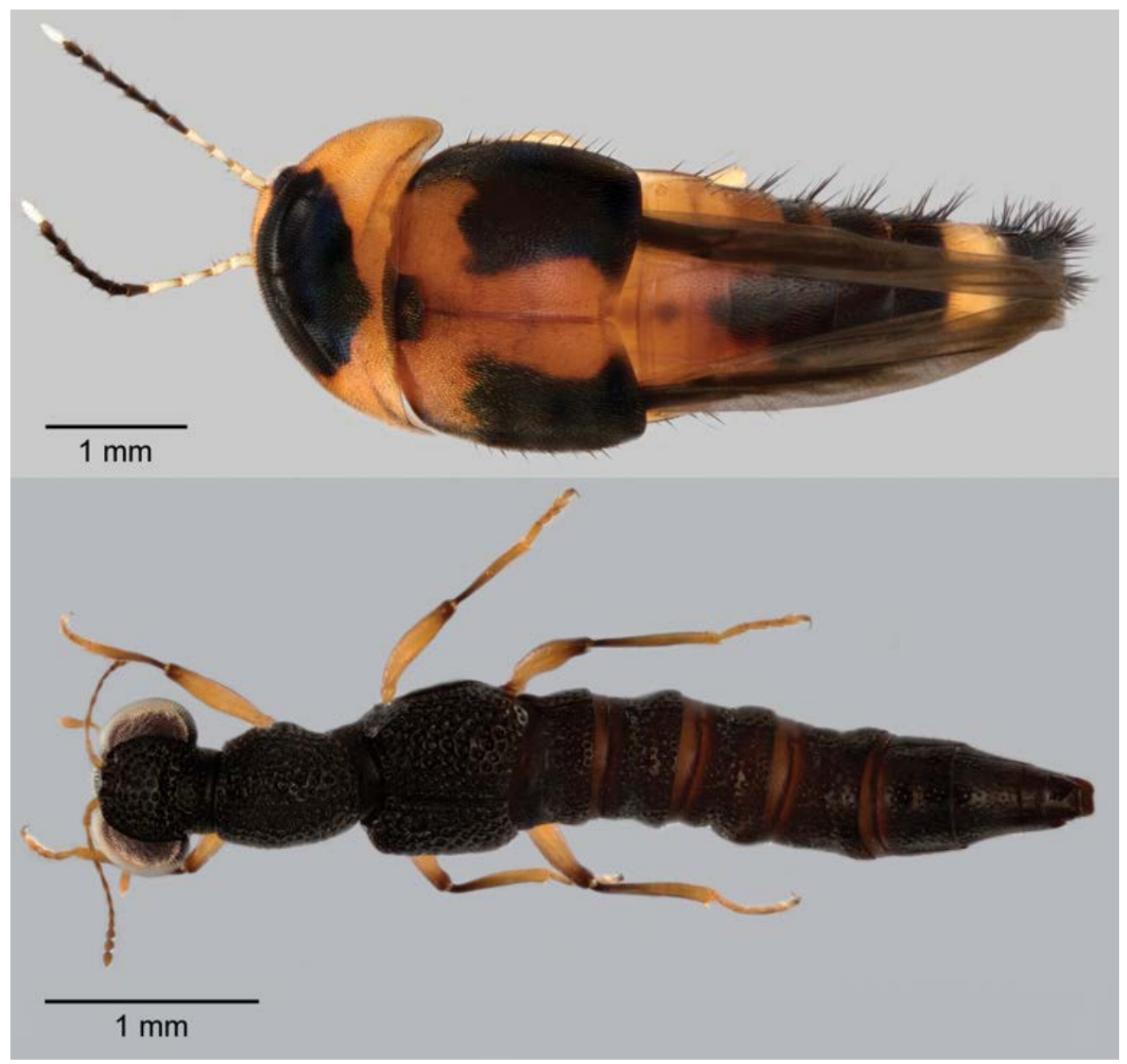

Fig. 8. Examples of Staphylinidae species found during the BTNR survey. (Photo: H. Siti Maimon)

\section{Diptera}

Diptera, or the true flies, are another extremely diverse group of insects with more than 180,000 described species. Many of the most common flies have a negative impact on humans. They include mosquitoes and houseflies, but Diptera are much more diverse than that. They include predators (e.g., Asilidae or the robber flies), nectarivorous species (e.g., Syrphidae, the hover flies), herbivorous species (Tephritidae, true fruit flies), and many parasites (e.g., Hippoboscidae, louse flies) or parasitoids (e.g., Pipunculidae, big-headed flies). Flies are important pollinators of plants and are just as important to the plant reproductive cycle as the more well-known hymenopterans or lepidopterans. True to their name, flies are among the most acrobatic and manoeuvrable of all flying creatures, aided by their excellent vision. Flies are characterised by a special pair of organs known as the halteres, which were originally a second pair of wings. These organs provide guidance to the fly in flight. They are so important for flight that flies that lose their halteres are unable to fly. 


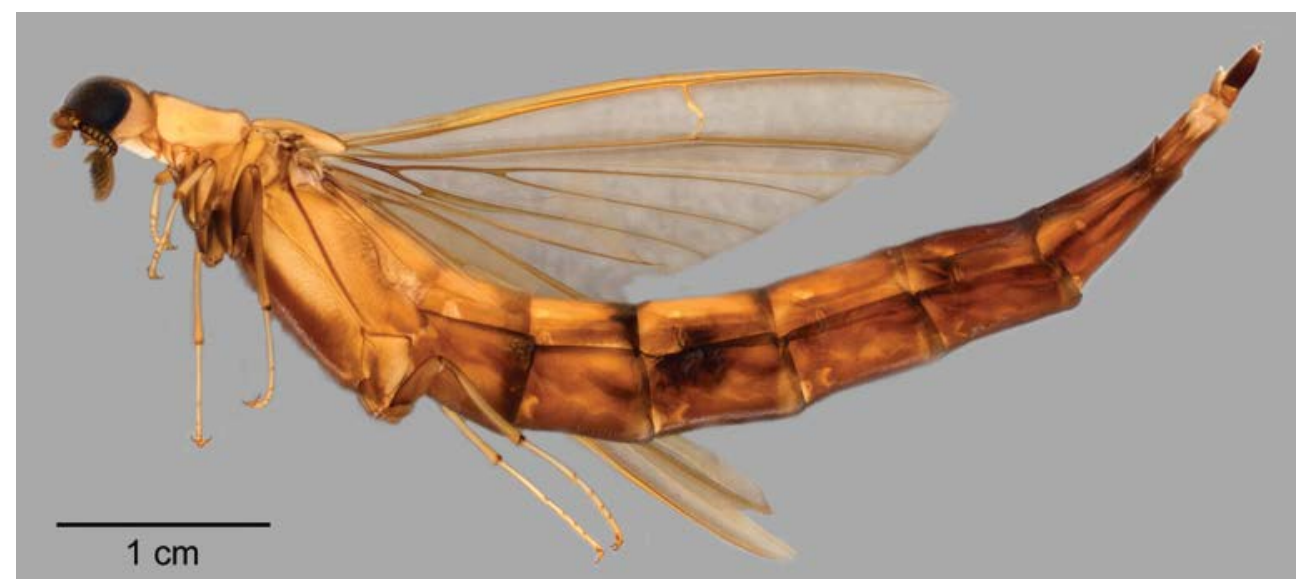

Fig. 9. A species of Lymexilidae from the genus Atractocerus found during the BTNR survey. (Photo: H. Siti Maimon)

\section{Pipunculidae (Big-headed flies)}

Pipunculidae get their common name from two huge eyes which take up almost their whole head (Fig. 11). Almost all species in this family are parasitoids that specialise in using hemipteran planthoppers as hosts for their young. Pipunculid eggs are laid on the body of the planthopper and the larvae will then feed on the living planthopper until the larvae are ready to pupate and become adults.

\section{Diopsidae (Stalk-eyed flies)}

Diopsidae is a family of Diptera that have gained attention due to their peculiar head morphology (Fig. 12). The eyes are mounted on stalks projecting from their head and the length of the eye stalks varies between the species (Baker \& Meier, 2002; Meier \& Hilger, 2002). Males in some genera have much longer eyestalks than females and experimental work indicates that in some species males with longer eyestalks are more likely to mate with females because they win male-male contests (Panhuis \& Wilkinson, 1999).

\section{Neuroptera}

Neuroptera, or net-winged insects, are an order of insects consisting of the lacewings, antlions, mantis-flies and their relatives (Fig. $13 \&$ 14). They have four wings with multiple veins, resembling a net, hence the name of the order. The larvae are ferocious predators, primarily hunting other insects and invertebrates. In contrast, adult neuropterans usually feed on nectar or do not feed at all. Exceptions such as mantis-flies exist, where both the larvae and the adults are predators.

\section{Cases of convergent evolution}

Insects include many striking cases of convergent evolution; i.e., the species look similar but are not closely related. Common reasons include mimicry, where one 


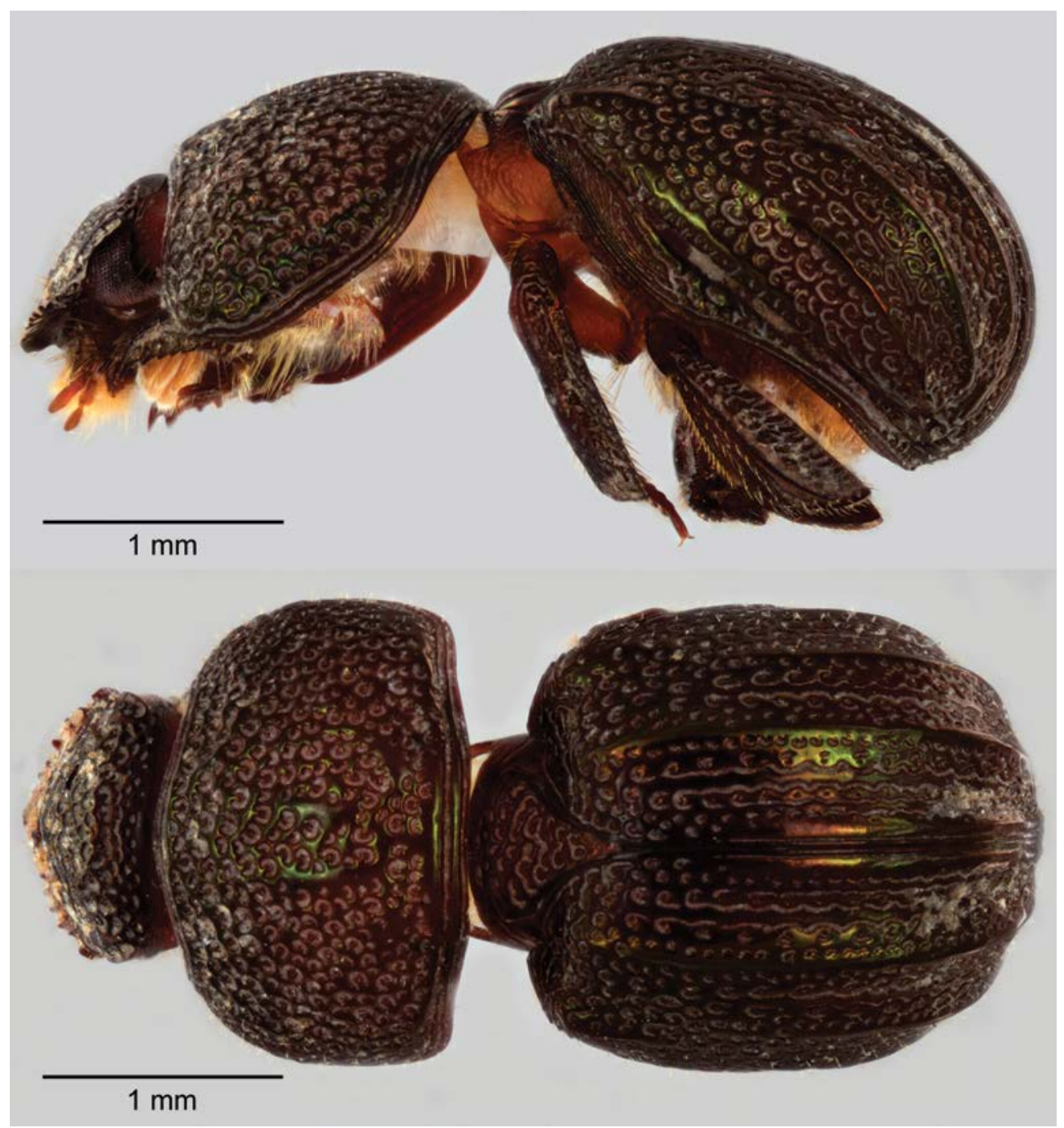

Fig. 10. A species of Hybosoridae found during the BTNR survey. (Photo: H. Siti Maimon)

insect species resembles another species in order to gain a benefit, or the species independently "invent" similar solutions for the same purpose. The BTNR survey illustrated many such cases of convergent evolution.

\section{Convergent evolution - Praying mantis and mantis-flies}

At first glance, praying mantises (Fig. 15) and the mantis-flies (Fig. 16) look very similar because both groups have heavily modified, raptorial forelegs. However, these two taxa are not at all closely related. Instead, they have independently evolved similarly modified raptorial forelegs that are used for seizing prey. 


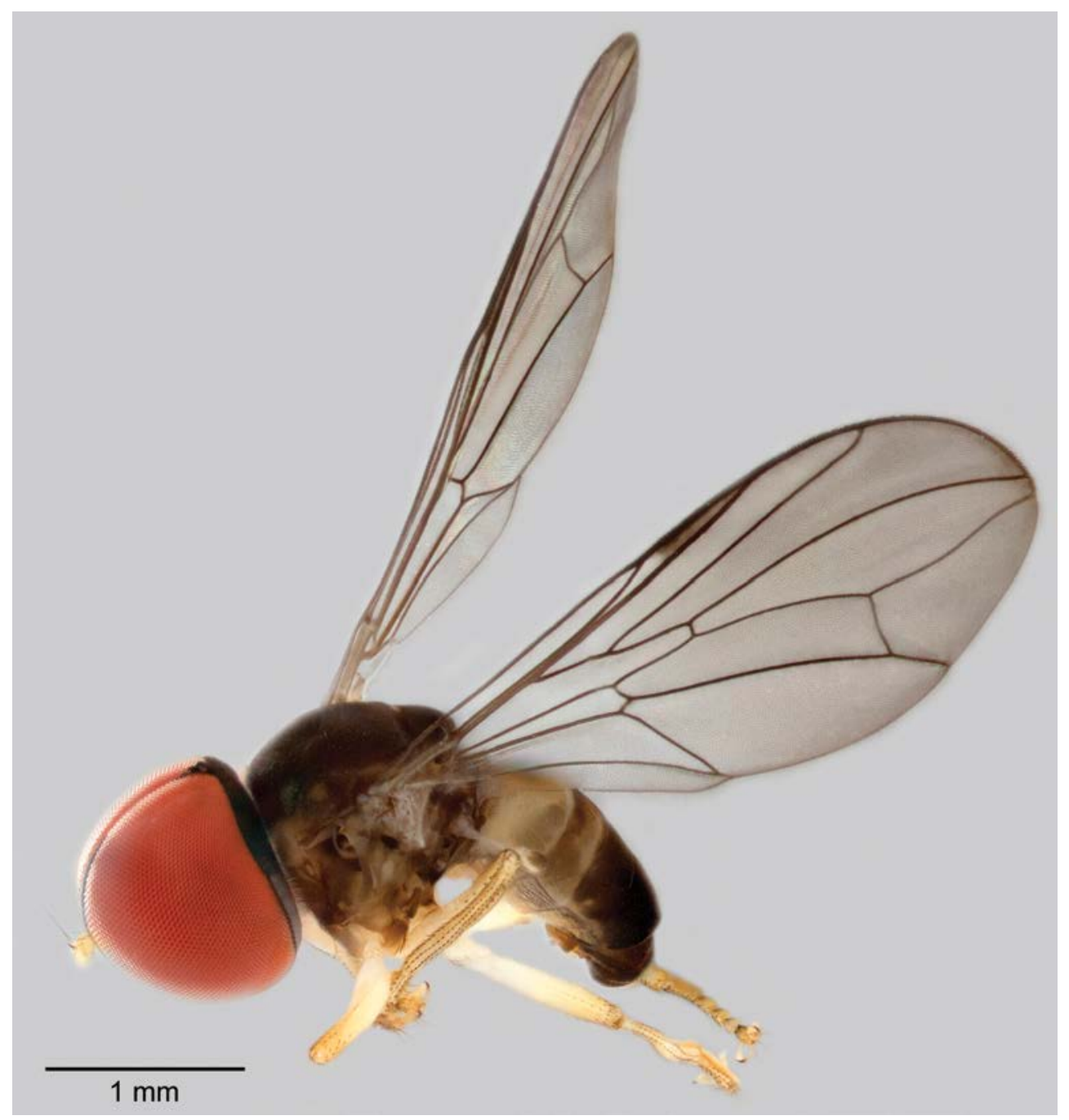

Fig. 11. A species of Pipunculidae found during the BTNR survey. (Photo: H. Siti Maimon)

Batesian mimicry - Leaf beetles and Beetle flies

Batesian mimicry is a form of mimicry where a harmless species imitates the appearance of another, more harmful species as a way of defending itself against predation. In this case, beetle flies (Celyphidae) resemble leaf beetles (Chrysomelidae) (Fig. 17), because many species of this family either produce toxins or accumulate plant toxins. This renders the beetles distasteful or poisonous to predators. Beetle flies (Fig. 18) lack such toxins, but are likely to fool predators because they look so similar to leaf beetles; i.e., the resemblance to beetles is a way for the beetle flies to protect themselves against predators. 


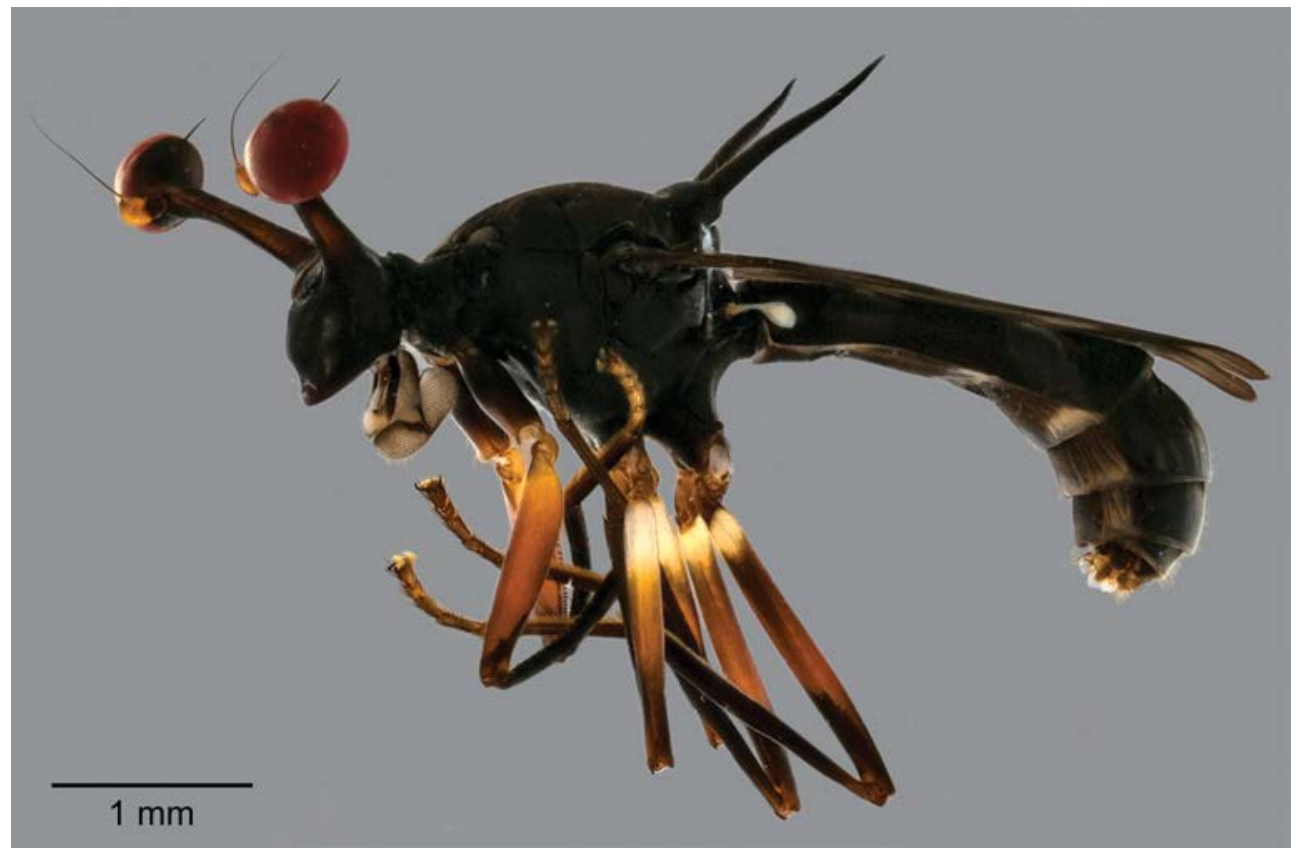

Fig. 12. A species of Diopsidae found during the BTNR survey. (Photo: H. Siti Maimon)

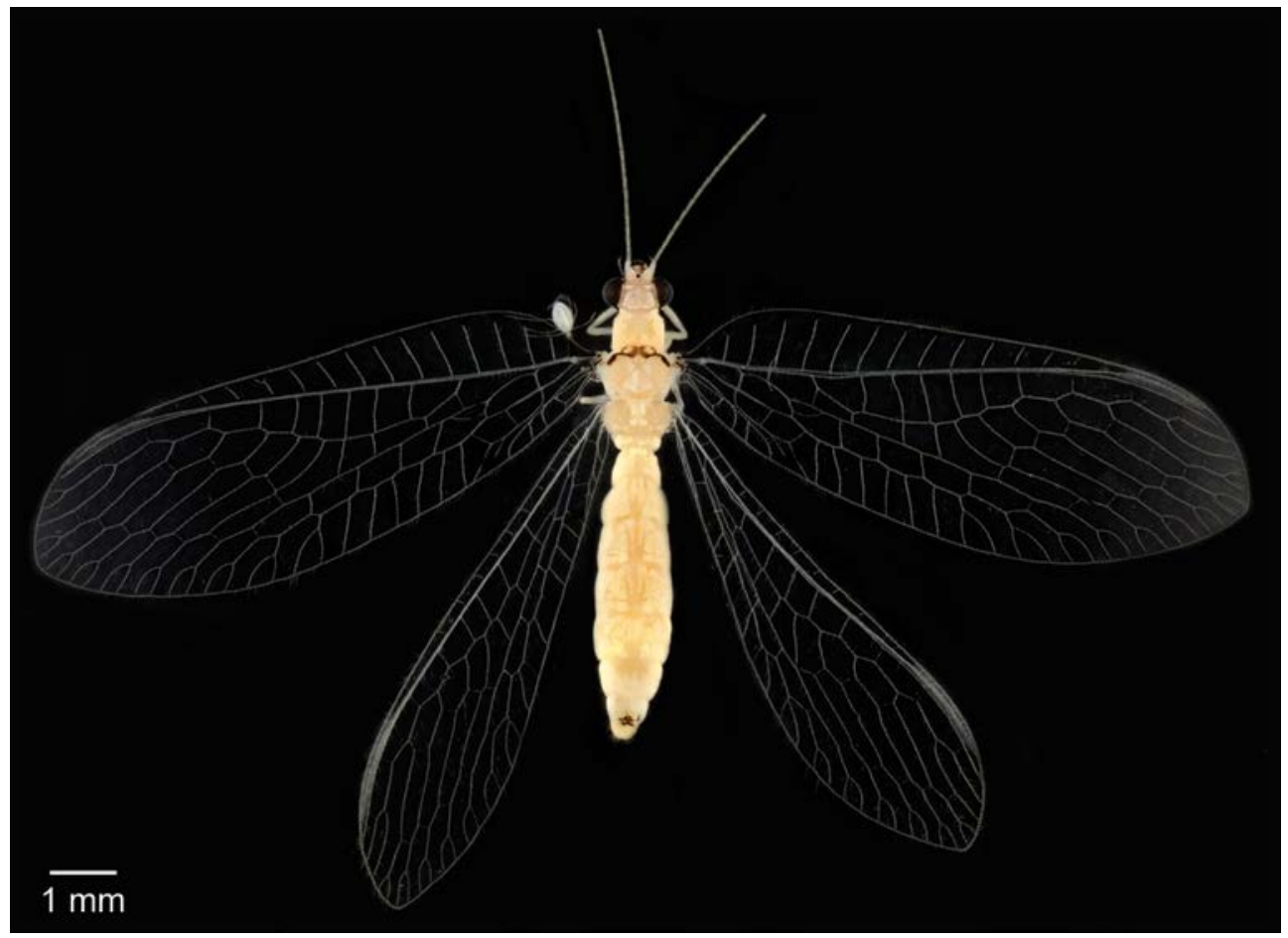

Fig. 13. A species of Neuroptera found during the BTNR survey. (Photo: H. Siti Maimon) 


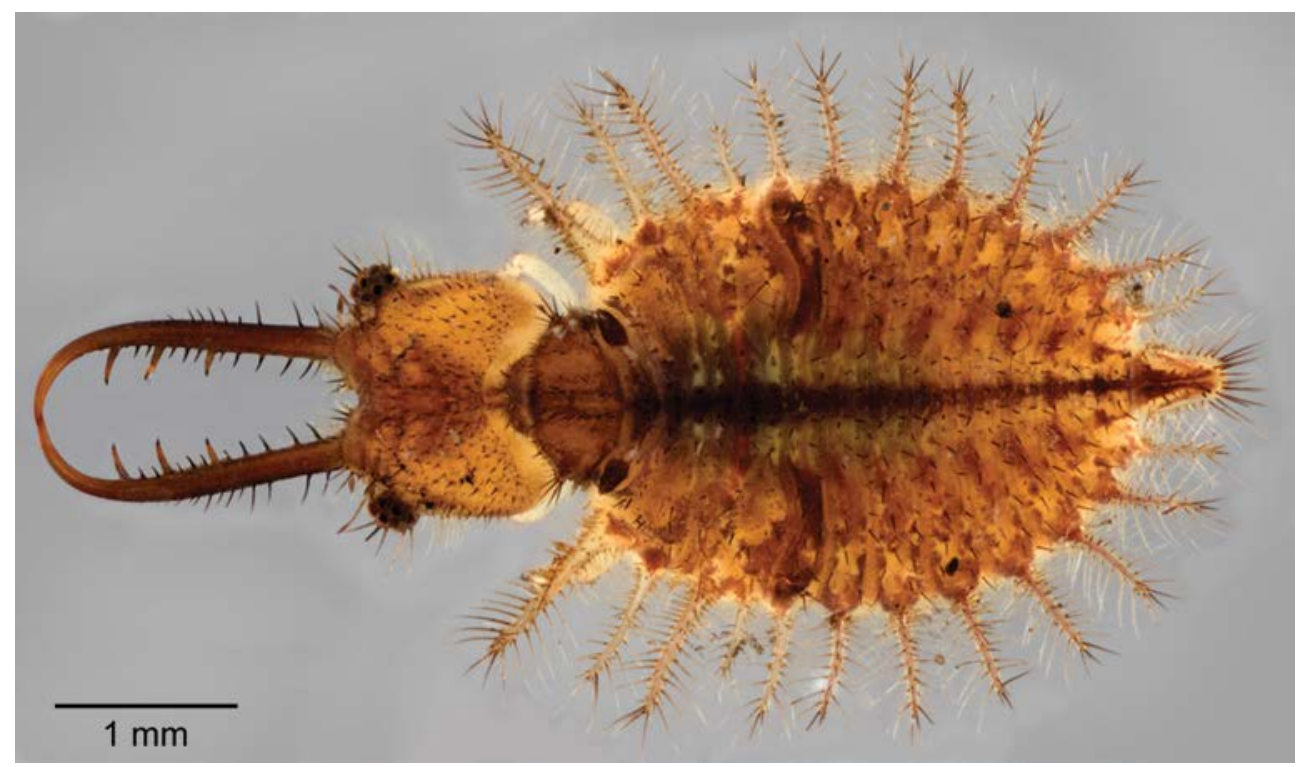

Fig. 14. A neuropteran larva, with massive, prominent jaws. The most famous neuropterans are ant-lions, whose larvae bury themselves in a pit of sand and wait to trap passing ants. (Photo: H. Siti Maimon)

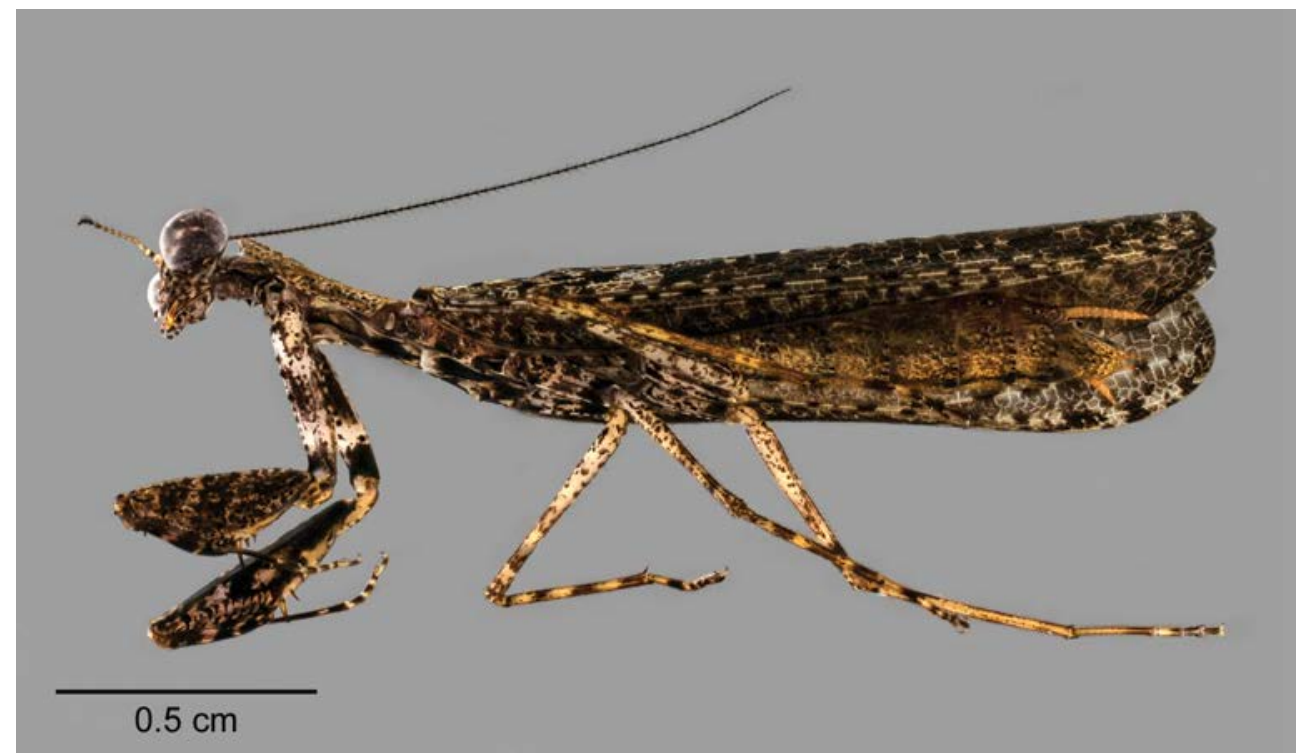

Fig. 15. A praying mantis from the order Mantodea. (Photo: H. Siti Maimon) 


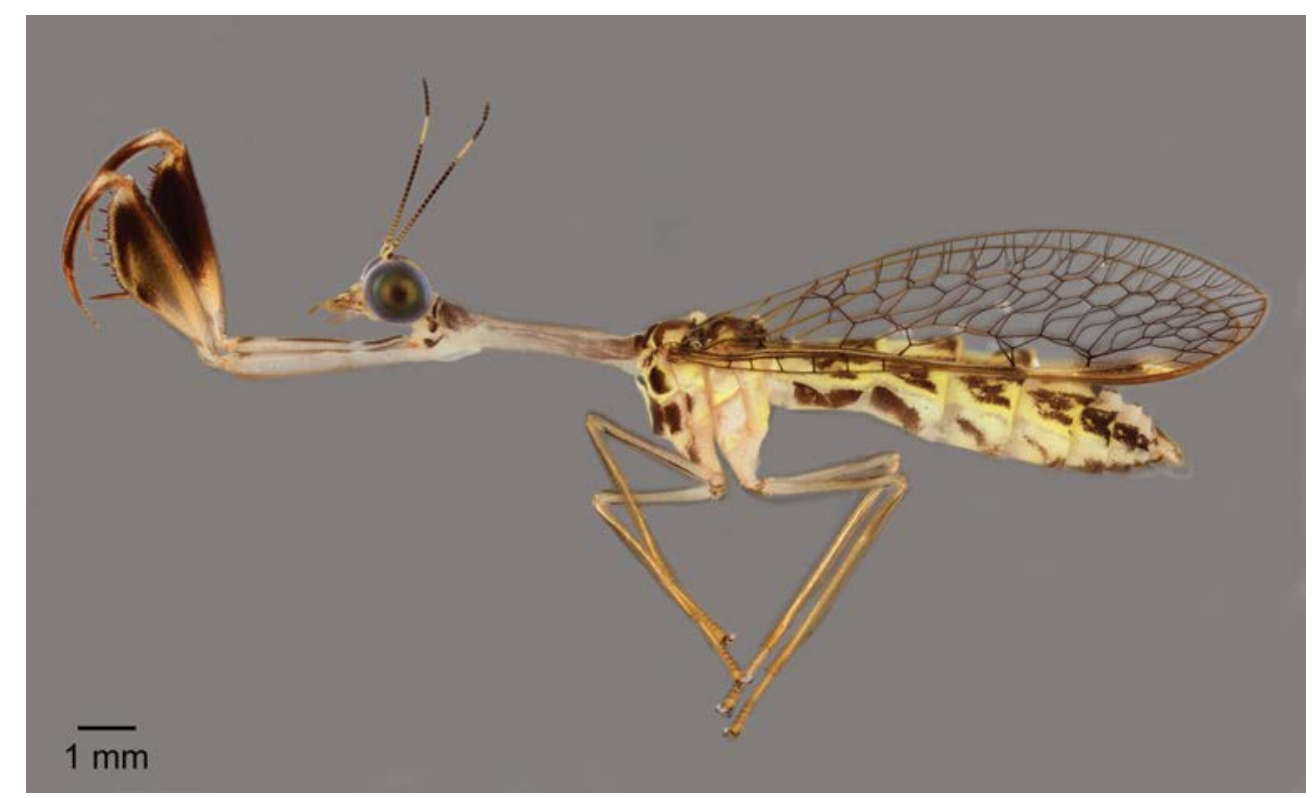

Fig. 16. A mantis-fly from the order Neuroptera. (Photo: H. Siti Maimon)

\section{Batesian mimicry - Soldier flies and hymenopterans}

Soldier flies are another group of Diptera which practice Batesian mimicry, with many species mimicking wasps or other hymenopterans which have painful stingers with which to defend themselves.

The soldier fly seen in Fig. 19 only has a single pair of functional wings, with the second pair of wings being developed into the pair of balancing organs known as the halteres. However, its colouration and wasp-like waist at the thorax-abdomen junction cause it to resemble a wasp or bee. Predators usually avoid wasps and bees due to the threat of being stung. Hence, the stratiomyid presumably gains protection from predators by resembling a wasp.

\section{Discussion}

The BTNR insect survey forms part of two larger studies. Firstly, it contributes to the comprehensive biodiversity survey of BTNR (Chan \& Davison, 2019). Secondly, it is part of a much larger initiative that is designed to generate baseline information on the insect diversity in Singapore. Due to the large number of species and specimens, this task is both difficult and important. It is difficult because it is likely that Singapore has more than 50,000 species of insects, a huge number compared to the more familiar vertebrates. The task is also important because collectively the insect species are predicted to contribute more animal biomass than all other animals combined as well as performing many important ecosystem roles: they pollinate, they decompose, they prey on other insects, they develop inside pest 


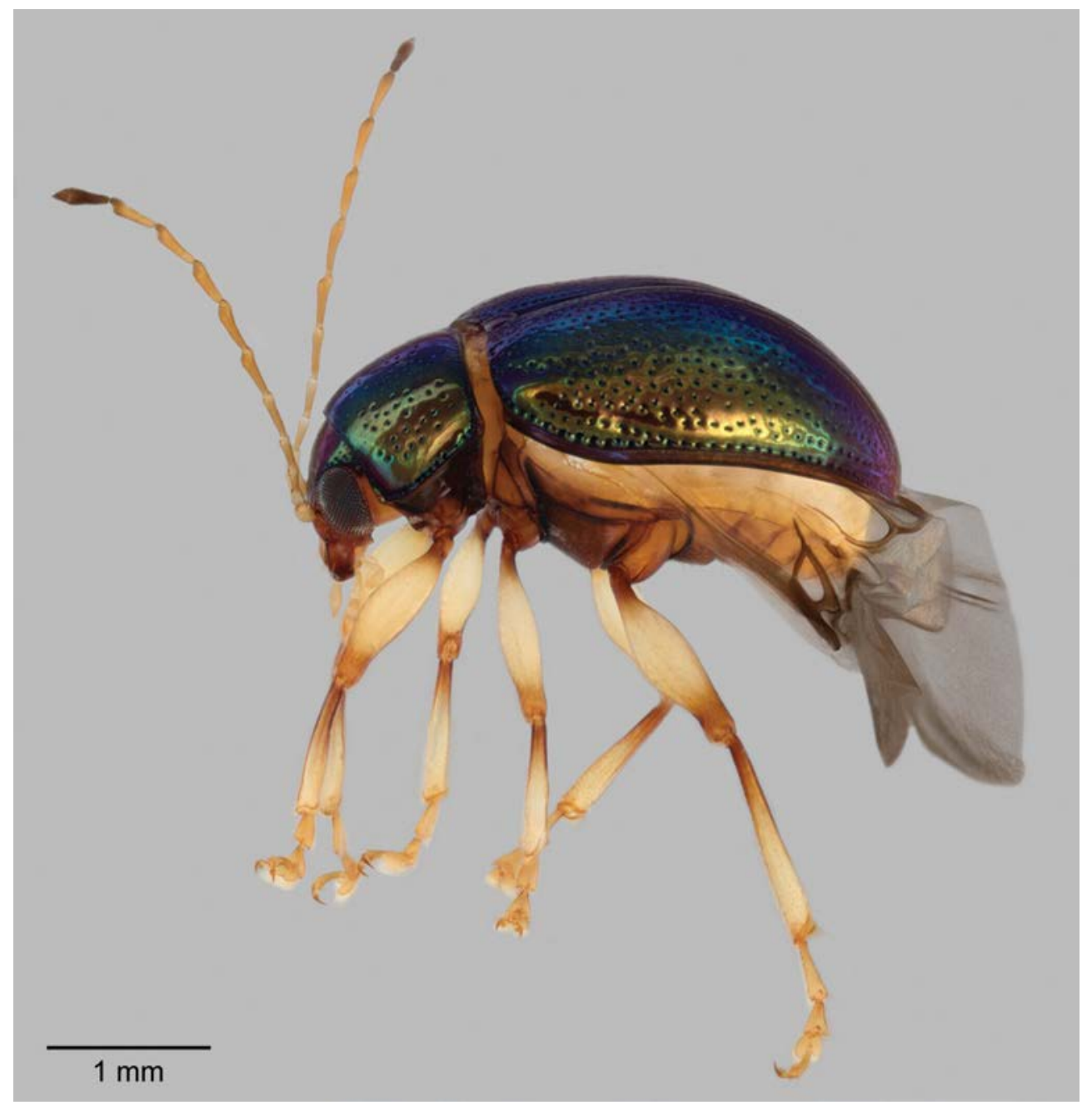

Fig. 17. A leaf beetle belonging to the family Chrysomelidae. The elytra of this species are round and iridescent. This renders the beetles fairly conspicuous, but they are protected by poisons that they obtain from their host plant. (Photo: H. Siti Maimon)

species, they spread fungal spores, they transmit viruses, and so on. Most of the time these species are out of sight and thus often out of mind, but occasionally humanity gains insights into why insects matter. A good example is the pollination crisis in agriculture that already costs billions of dollars per year (Klein et al., 2007). There is now evidence for a worldwide decline in insect populations in many countries (Biesmeijer et al., 2006; Hallmann et al., 2017). This is likely to cause numerous environmental problems. After all, E. O. Wilson already predicted "If all mankind were to disappear, the world would regenerate back to the rich state of equilibrium that existed ten thousand years ago. If insects were to vanish, the environment would collapse into chaos." 


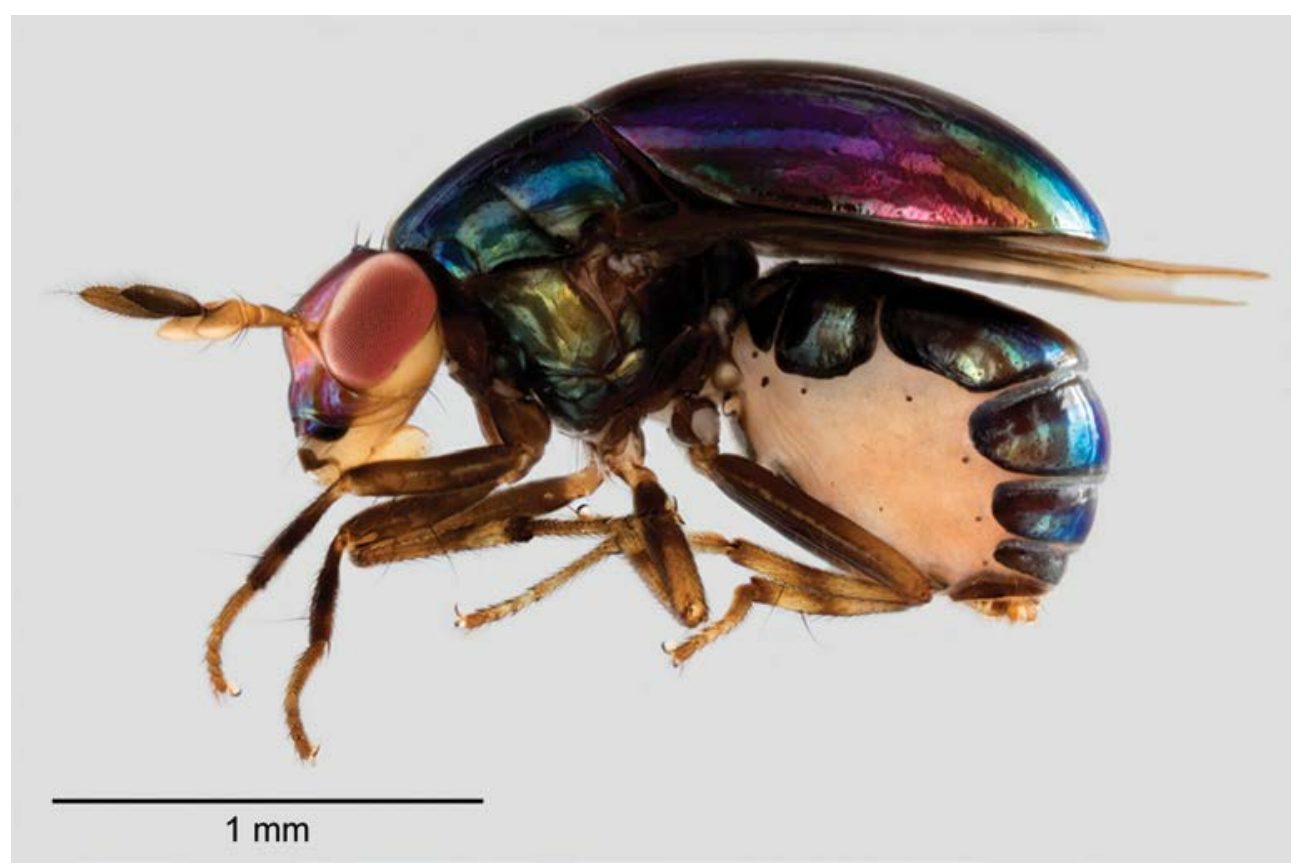

Fig.18. A beetle-fly from the genus Acelyphus (family Celyphidae). The scutellum of the fly has expanded to imitate a true beetle's elytra and is as iridescent as an actual leaf beetle's exoskeleton. (Photo: H. Siti Maimon)

Our study suggests that BTNR may be home to many rare forest-dwelling species that are likely not to be found elsewhere in Singapore because BTNR is one of the few places in Singapore that has never been fully cleared of its original vegetative cover. Our results also suggest that the insect fauna of BTNR is very species-rich. We here have only analysed a small proportion of the diversity (Hemipteran), but we predict that similar results will be found for other insect orders that are even more species-rich such as Hymenoptera (ants, bees and wasps) (Ascher et al., 2019) or Diptera (flies).

In order to continue building on the results obtained so far, much more work needs to be carried out, both in BTNR as well as other habitats in Singapore. It would be helpful if future work included an expansion and a diversification of the methods used to sample insect diversity. There are other trapping techniques that are likely to reveal many additional species (e.g., flight intercept traps, pitfall traps) and thus contribute to obtaining a more complete picture. Efforts must also be taken to ensure all data obtained are properly catalogued and stored in an easily accessible database, and that both genetic data and physical specimens are stored and accessioned properly in a natural history institution so as to make them easily available for future scientific work. 


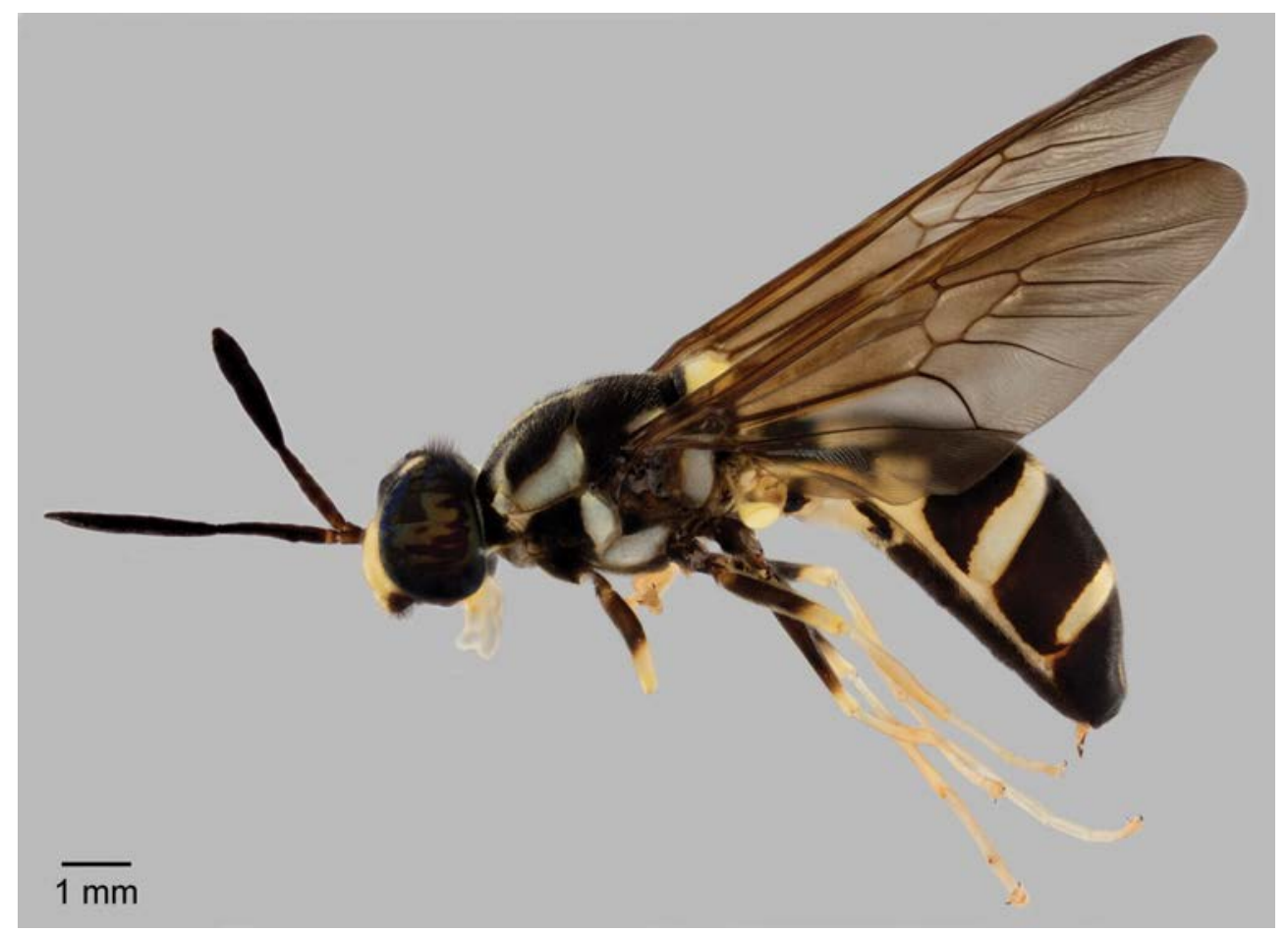

Fig.19. A soldier fly from the family Stratiomydiae, in the order Diptera. This soldier fly is from the species Hermetia laeta. (Photo: H. Siti Maimon)

A properly curated and expanding database of insect images and genetic information will be an important part of such cataloguing because it allows for follow-up studies ranging from diet to population genetics. For example, a database of plant genetic barcodes was essential for identifying the food plants of Raffles' Banded Langur (Srivathsan et al. 2016), one of the most endangered primates in Singapore. Generating DNA barcodes for insects is similarly important for diet studies of endangered insectivores such as the pangolin, and will aid in their conservation. The existence of DNA barcodes in a biodiversity database can also be used to match the adult stages of holometabolous insects with their larval stages (Yeo et al., 2018). This allows for detecting the presence of species in the environment even without their physical capture or sampling, via the use of environmental DNA ["eDNA" (Lim et al., 2016)]. The evaluation of eDNA would be less informative without first obtaining a DNA barcode database. Thus, there are many incentives for continuing with surveying the biodiversity of Singapore. It is equally important to present the results to the public via high-resolution and high-magnification images. The species found in BTNR will be added to the website "Biodiversity of Singapore", which is accessible to the public. 
The process of species discovery takes time, but modern technology has made it faster and easier. The prospect of completely sequencing, DNA barcoding, and identifying the entire biodiversity of a country is now no longer a wildly optimistic dream, but an achievable goal.

ACKNOWLEDGEMENTS. All work described here was carried out as part of the Bukit Timah Nature Reserve Comprehensive Biodiversity Survey carried out in collaboration and with support from the National Parks Board of Singapore (NParks). Special thanks go to the team from the National Biodiversity Centre of NParks (Lena Chan, Jayasri Lakshminarayanan, Daniel Ng, Li Tianjiao, Zhou Boyi, Joanna Yeo Mei Ling, and Samantha Lai) as well as the NParks management team of BTNR (Sharon Chan, Cheryl Chia, Sunia Teo, Lee Lai Seng). We would also like to thank the research staff, lab technicians, undergraduate students and interns of the Evolutionary Biology Laboratory for their help and assistance. This project would have been impossible without their hard work. Lastly, we would like to acknowledge a grant by the Ministry of Education (R-154-000-A22-112) which is currently supporting insect surveys across Singapore.

\section{References}

Ang, Y., Puniamoorthy, J., Pont, A.C., Bartak, M., Blanckenhorn, W.U., Eberhard, W.G., Puniamoorthy, N., Silva, V.C., Munari, L. \& Meier, R. (2013a). A plea for digital reference collections and other science-based digitization initiatives in taxonomy: Sepsidnet as exemplar. Syst. Entomol. 38: 637-644.

Ang, Y., Wong, L.J. \& Meier, R. (2013b). Using seemingly unnecessary illustrations to improve the diagnostic usefulness of descriptions in taxonomy-a case study on Perochaeta orientalis (Diptera, Sepsidae). ZooKeys 355: 9-27.

Ascher, J.S., Soh, Z.W.W., Ho, B.M., Lee, R.Y.Y., Leong, A.Q.E., Chui, S.X., Lai, J.J.L., Lee, J.X.Q., Foo, M. \& Soh, E.J.Y. (2019). Bees of the Bukit Timah Nature Reserve and its vicinity, Singapore. Gard. Bull. Singapore 71 (Suppl. 1): 245-271.

Ashton, P.S., Boscolo, M., Liu, J. \& LaFrankie, J.V. (1999). A global programme in interdisciplinary forest research: the CTFS perspective. J. Trop. For. Sci. 11: 180-204.

Baker, R., \& Meier, R. (2002). A cladistic analysis of Diopsidae (Diptera) based on morphological and DNA sequence data. Insect Syst. Evol. 33: 325-336.

Balke, M., Hendrich, L. \& Yang, C.M. (1997). Water Beetles (Insecta: Coleoptera) in the Nature Reserves of Singapore. Proceedings of the Nature Reserves Survey Seminar. Gard. Bull. Singapore 49: 321-331.

Baloğlu, B., Clews, E. \& Meier, R. (2018). NGS barcoding reveals high resistance of a hyperdiverse chironomid (Diptera) swamp fauna against invasion from adjacent freshwater reservoirs. Front. Zool. 15: 31.

Bar-On, Y.M., Phillips, R. \& Milo, R. (2018). The biomass distribution on Earth. Proc. Natl. Acad. Sci. U.S.A. 115: 6506-6511.

Biesmeijer, J.C., Roberts, S.P.M., Reemer, M., Ohlemüller, R., Edwards, M., Peeters, T., Schaffers, A.P., Potts, S.G., Kleukers, R., Thomas, C.D., Settele, J. \& Kunin, W.E. (2006). Parallel declines in pollinators and insect-pollinated plants in Britain and the Netherlands. Science 313: 351-354. 
Brook, B.W., Sodhi, N.S. \& Ng, P.K.L. (2003). Catastrophic extinctions follow deforestation in Singapore. Nature 424: 420-426.

Chan, L. \& Davison, G.W.H. (2019). Introduction to the Comprehensive Biodiversity Survey of Bukit Timah Nature Reserve, Singapore. Singapore. Gard. Bull. Singapore 71 (Suppl. 1): 3-17.

Cheong, L.F. (2019). Estimating saproxylic beetle (Coleoptera: Cerambycidae and Buprestidae) diversity in Bukit Timah Nature Reserve, Singapore, with a methodological and biological review. Gard. Bull. Singapore 71 (Suppl. 1): 341-370.

Coddington, J.A., Agnarsson, I., Miller, J.A., Kuntner, M. \& Hormiga, G. (2009). Undersampling bias: the null hypothesis for singleton species in tropical arthropod surveys. J. Anim. Ecol. 78: 573-584.

Corlett, R.T. (1988). Bukit Timah: the history and significance of a small rain-forest reserve. Environ. Conserv. 15: 37-44.

Cranston, P.S., Ang, Y.C., Heyzer, A., Lim, R.B.H., Wong, W.H., Woodford, J.M. \& Meier, R. (2013). The nuisance midges (Diptera: Chironomidae) of Singapore's Pandan and Bedok reservoirs. Raffles Bull. Zool. 61: 779-793.

Ercelawn, A.C., LaFrankie J.V., Lum S.K.Y., \& Lee S.K. (1998). Short-term recruitment of trees in a forest fragment in Singapore. Tropics 8: 105-115.

Forbes, A.A., Bagley, R.K., Beer, M.A., Hippee, A.C. \& Widmayer, H.A. (2018). Quantifying the unquantifiable: why Hymenoptera, not Coleoptera, is the most speciose animal order. BMC Ecol. 18: 21.

Giangrande, A. (2003). Biodiversity, conservation, and the 'Taxonomic impediment.' Aquat. Conserv. Mar. Freshw. Ecosyst. 13: 451-459.

Goldsmith, G.R., Comita, L.S. \& Chua, S.C. (2011). Evidence for arrested succession within a tropical forest fragment in Singapore. J. Trop. Ecol. 27: 323-326.

Green, S.V. (1998). The taxonomic impediment in orthopteran research and conservation. $J$. Insect Conserv. 2: 151-159.

Grootaert, P. (2006). The genus Teuchophorus (Diptera, Dolichopodidae) in Singapore. Raffles Bull. Zool. 54: 59-82.

Grootaert, P. (2018). Revision of the genus Thinophilus Wahlberg (Diptera: Dolichopodidae) from Singapore and adjacent regions: A long term study with a prudent reconciliation of a genetic to a classic morphological approach. Raffles Bull. Zool. 66: 413-473.

Grootaert, P. \& Puniamoorthy, J. (2014). Revision of Ngirhaphium (Insecta: Diptera: Dolichopodidae), with the description of two new species from Singapore's mangroves. Raffles Bull. Zool. 62: 146-160.

Grootaert, P. \& Shamshev, I. (2015). New species of fast-running flies (Diptera: Empidoidea, Hybotidae, Tachydromiinae) from mangroves in Singapore. Raffles Bull. Zool. 63: 583-609.

Hallmann, C.A., Sorg, M., Jongejans, E., Siepel, H., Hofland, N., Schwan, H., Stenmans, W., Müller, A., Sumser, H., Hörren, T., Goulson, D. \& de Kroon, H. (2017). More than 75 percent decline over 27 years in total flying insect biomass in protected areas. PLoS One 12: $\mathrm{e} 0185809$.

Hebert, P.D.N., Cywinska, A., Ball, S.L. \& deWaard, J.R. (2003). Biological identifications through DNA barcodes. Proc. R. Soc. Lond. B 270: 313-321.

Henderson, J.C. (2000). The survival of a forest fragment: Bukit Timah Nature Reserve, Singapore. In: Font, X., \& Tribe, J. (eds) Forest Tourism and Recreation: Case Studies in Environmental Management, pp. 23-39. Wallingford, United Kingdom: CABI. 
Ho, B.C., Lua, H.K., Bazilah Ibrahim, Yeo, R.S.W., Athen, P., Leong, P.K.F., Ali Ibrahim, Koh, S.L., Hassan Ibrahim, Lindsay, S., Chin, L.L., Seah, W.W. \& Middleton, D.J. (2019). The plant diversity in Bukit Timah Nature Reserve, Singapore. Singapore. Gard. Bull. Singapore 71 (Suppl. 1): 41-134.

Kim, K.C. \& Byrne, L.B. (2006). Biodiversity loss and the taxonomic bottleneck: emerging biodiversity science. Ecol. Res. 21: 794.

Klein, A.-M., Vaissière, B.E., Cane, J.H., Steffan-Dewenter, I., Cunningham, S.A., Kremen, C. \& Tscharntke, T. (2007). Importance of pollinators in changing landscapes for world crops. Proc. R. Soc. Lond. B 274: 303-313.

Kutty, S.N., Wang, W., Ang, Y., Tay, Y.C., Ho, J.K.I. \& Meier, R. (2018). Next-Generation identification tools for Nee Soon freshwater swamp forest, Singapore. Gard. Bull. Singapore 70 (Suppl. 1): 155-173.

Lee, J.S.H., Lee, I.Q.W., Lim, S.L.H., Huijbregts, J. \& Sodhi, N.S. (2009). Changes in dung beetle communities along a gradient of tropical forest disturbance in South-East Asia. J. Trop. Ecol. 25: 677-680.

Lim, G.S., Balke, M. \& Meier, R. (2012). Determining species boundaries in a world full of rarity: singletons, species delimitation methods. Syst. Biol. 61: 165-169.

Lim, K.S. (2019). Birds of Bukit Timah Nature Reserve, Singapore. Singapore. Gard. Bull. Singapore 71 (Suppl. 1): 185-208.

Lim, N.K.M., Tay, Y.C., Srivathsan, A., Tan, J.W.T., Kwik, J.T.B., Baloğlu, B., Meier, R. \& Yeo, D.C.J. (2016). Next-generation freshwater bioassessment: eDNA metabarcoding with a conserved metazoan primer reveals species-rich and reservoir-specific communities. R. Soc. Open Sci. 3: 160635.

Liow, L.H., Sodhi, N.S. \& Elmqvist, T. (2001). Bee diversity along a disturbance gradient in tropical lowland forests of South-east Asia. J. Appl. Ecol. 38: 180-192.

Meier, R. (2008). DNA Sequences in Taxonomy. In: Wheeler, Q.D. (ed.) The New Taxonomy, pp. 95-127. Boca Raton: CRC Press.

Meier, R. \& Hilger, S. (2002). On the egg morphology and phylogenetic relationships of Diopsidae (Diptera: Schizophora). J. Zool. Syst. Evol. Res. 38: 1-36.

Meier, R., Shiyang, K., Vaidya, G., Ng, P.K.L. \& Hedin, M. (2006). DNA barcoding and taxonomy in Diptera: a tale of high intraspecific variability and low identification success. Syst. Biol. 55: 715-728.

Meier, R., Zhang, G. \& Ali, F. (2008). The use of mean instead of smallest interspecific distances exaggerates the size of the "barcoding gap" and leads to misidentification. Syst. Biol. 57: 809-813.

Meier, R., Wong, W., Srivathsan, A. \& Foo, M. (2016). \$1 DNA barcodes for reconstructing complex phenomes and finding rare species in specimen-rich samples. Cladistics 32: $100-110$.

Murphy, D.H. (1997). Odonata biodiversity in the Nature Reserves of Singapore. Proceedings of the Nature Reserves Survey Seminar. Gard. Bull. Singapore 49: 333-352.

Ng, P.K.L. (1997). The conservation status of freshwater prawns and crabs in Singapore with emphasis on the nature reserves. Proceedings of the Nature Reserves Survey Seminar. Gard. Bull. Singapore 49: 267-272.

Ong, X.R., Chua, S.C.H. \& Potts, M.D. (2013). Recent records of the dung beetle Catharsius molossus (Coleoptera: Scarabaeidae) in Singapore. Nat. Singapore 6: 1-6.

Panhuis, T.M., \& Wilkinson, G.S. (1999). Exaggerated male eye span influences contest outcome in stalk-eyed flies (Diopsidae). Behav. Ecol. Sociobiol. 46: 221-227. 
Seago, A.E., Brady, P., Vigneron, J.-P. \& Schultz, T.D. (2009). Gold bugs and beyond: a review of iridescence and structural colour mechanisms in beetles (Coleoptera). J. R. Soc. Interface 6: S165-S184.

Seow-Choen, F. (1997). Stick and Leaf Insect (Phasmida: Insecta) Biodiversity in the Nature Reserves of Singapore. Proceedings of the Nature Reserves Survey Seminar. Gard. Bull. Singapore 49: 297-312.

Shamshev, I.V. \& Grootaert, P. (2007). Revision of the genus Elaphropeza Macquart (Diptera: Hybotidae) from the Oriental Region, with a special attention to the fauna of Singapore. Zootaxa 1488: 1-164.

Srivathsan, A. \& Meier, R. (2012). On the inappropriate use of Kimura-2-parameter (K2P) divergences in the DNA-barcoding literature. Cladistics 28: 190-194.

Srivathsan, A., Sha, J.C.M., Vogler, A.P. \& Meier, R. (2015). Comparing the effectiveness of metagenomics and metabarcoding for diet analysis of a leaf-feeding monkey (Pygathrix nemaeus). Mol. Ecol. Resour. 15: 250-261.

Srivathsan, A., Ang, A., Vogler, A.P. \& Meier, R. (2016). Fecal metagenomics for the simultaneous assessment of diet, parasites, and population genetics of an understudied primate. Front. Zool. 13: 17.

Srivathsan, A., Baloğlu, B., Wang, W., Tan, W.X., Bertrand, D., Ng, A.H.Q., Boey, E.J.H., Koh, J.J.Y., Nagarajan, N. \& Meier, R. (2018). A MinION ${ }^{\mathrm{TM}}$-based pipeline for fast and cost-effective DNA barcoding. Mol. Ecol. Resour. 18: 1035-1049.

Stork, N.E. (2018). How many species of insects and other terrestrial arthropods are there on earth? Annu. Rev. Entomol. 63: 31-45.

Stork, N.E., McBroom, J., Gely, C. \& Hamilton, A.J. (2015). New approaches narrow global species estimates for beetles, insects, and terrestrial arthropods. Proc. Natl. Acad. Sci. U.S.A. 112: 7519-7523.

Tan, M.K. (2012a). Orthoptera in the Bukit Timah and Central Catchment Nature Reserves (Part 1): Suborder Caelifera. Singapore: Raffles Museum of Biodiversity Research, National University of Singapore.

Tan, M.K. (2012b). Orthoptera in the Bukit Timah and Central Catchment Nature Reserves (Part 2): Suborder Ensifera. Singapore: Raffles Museum of Biodiversity Research, National University of Singapore.

Tay, Y.C., Chng, M.W.P., Sew, W.W.G., Rheindt, F.E., Tun, K.P.P. \& Meier, R. (2016). Beyond the Coral Triangle: high genetic diversity and near panmixia in Singapore's populations of the broadcast spawning sea star Protoreaster nodosus. R. Soc. Open Sci. 3: 160253.

Teo, R.C.H. \& Thomas, N.J. (2019). Updated inventory of amphibians, reptiles and mammals of the Bukit Timah Nature Reserve, Singapore. Gard. Bull. Singapore 71 (Suppl. 1): $145-183$.

Turner, I.M. \& Corlett, R.T. (1996). The conservation value of small, isolated fragments of lowland tropical rain forest. Trends Ecol. Evol. 11: 330-333.

Wang, W.Y., Srivathsan, A., Foo, M., Yamane, S.K. \& Meier, R. (2018). Sorting specimen-rich invertebrate samples with cost-effective NGS barcodes: Validating a reverse workflow for specimen processing. Mol. Ecol. Resour. 18: 490-501.

Wong, J., Foo, M., Tan, H.T.W. \& Meier, R. (2017). Whitefly predation and extensive mesonotum color polymorphism in an Acletoxenus population from Singapore (Diptera, Drosophilidae). ZooKeys 725: 49-69.

Wong, W.H., Tay, Y.C., Puniamoorthy, J., Balke, M., Cranston, P.S. \& Meier, R. (2014). 'Direct PCR' optimization yields a rapid, cost-effective, nondestructive and efficient method for obtaining DNA barcodes without DNA extraction. Mol. Ecol. Resour. 14: 1271-1280. 
Yang, C.M., Lua, H.K. \& Yeo, K.L. (1997). Semi-aquatic bug (Heteromorpha: Gerromorpha) fauna in the Nature Reserves of Singapore. Proceedings of the Nature Reserves Survey Seminar. Gard. Bull. Singapore 49: 313-320.

Yeo, D., Puniamoorthy, J., Ngiam, R.W.J. \& Meier, R. (2018). Towards holomorphology in entomology: rapid and cost-effective adult-larva matching using NGS barcodes. Syst. Entomol. 43: 678-691.

Zhang, L., Yang, D. \& Grootaert, P. (2008). Mangrove Hercostomus sensu lato (Diptera: Dolichopodidae) of Singapore. Raffles Bull. Zool. 56: 17-28. 